\title{
REVIEW
}

\section{Malignant Transformation and Associated Biomarkers of Ovarian Endometriosis: A Narrative Review}

\author{
Liudmila M. Mikhaleva · Aleksandr I. Davydov • Olga I. Patsap • \\ Elizaveta V. Mikhaylenko • Vladimir N. Nikolenko • Margarita E. Neganova • \\ Sergey G. Klochkov · Siva G. Somasundaram • Cecil E. Kirkland • \\ Gjumrakch Aliev (1)
}

Received: March 13, 2020 / Published online: May 8, 2020

(C) The Author(s) 2020

\begin{abstract}
This review focuses on pathogenesis of endometriosis, its possible biomarkers and role in endometriosis-associated ovarian cancer. We analyzed various databases to obtain new insights, theories, and biomarkers associated with endometriosis. There are several theories of endometriosis development and biomarker
\end{abstract}

Digital Features To view digital features for this article go to https://doi.org/10.6084/m9.figshare.12179421.

L. M. Mikhaleva · G. Aliev ( $₫)$

Department of Clinical Pathology, Federal State

Budgetary Institution "Research Institute of Human

Morphology", 3, Tsyurupy Str, Moscow 117418,

Russian Federation

e-mail: cobalt55@gallyinternational.com;

aliev03@gmail.com

\section{A. I. Davydov}

Department of Obstetrics, Gynecology and

Perinatology, Institute of Clinical Medicine, I.M.

Sechenov First Moscow State Medical University

(Sechenov University), 8/2, Trubetskaya Str.,

Moscow 119991, Russian Federation

A. I. Davydov · O. I. Patsap

Department of Pathology, City Clinical Hospital After Named S.S. Udina, 4, Bld., 3, Kolomensky

Passage, Moscow 115446, Russian Federation

E. V. Mikhaylenko - V. N. Nikolenko - G. Aliev

I. M. Sechenov First Moscow State Medical

University of the Ministry of Health of the Russian

Federation (Sechenov University), 8/2 Trubetskaya

Str, Moscow 119991, Russia changes including atypical forms. A number of studies have attempted to establish specific, reliable biomarkers to help diagnose endometriosis and endometriosis-associated diseases on the basis of different pathogenetic pathways. Nevertheless, despite intensive research extending even to the molecular level, the origin, natural history, malignant transformation, and laboratory management of endometriosis and related diseases are not yet clearly defined. Therefore, early laboratory diagnoses of endometriosis, its atypical form, and

V. N. Nikolenko

Department of Normal and Topographic Anatomy, M.V. Lomonosov Moscow State University, Leninskie Gory, 1, Moscow 119991, Russia

M. E. Neganova · S. G. Klochkov · G. Aliev Institute of Physiologically Active Compounds, Russian Academy of Sciences, 1 Severny pr, Chernogolovka, Moscow Region 142432, Russia

S. G. Somasundaram · C. E. Kirkland

Department of Biological Sciences, Salem University, Salem, WV 26426, USA

G. Aliev

GALLY International Research Institute, 7733 Louis Pasteur Drive, \#330, San Antonio, TX 78229, USA 
endometriosis-associated ovarian tumors are important problems that require further study in the context of advanced therapeutic strategies to provide maximal health benefits to patients.

Keywords: Biomarkers; associated tumors; pathogenesis; Prognosis of endometriosis; Treatment of endometriosis; Women's health

\section{Key Summary Points}

Ovarian endometriosis is one of the leading causes of female infertility and is a known risk factor for the development of ovarian cancer.

The review summarizes data in current literature evidence about ovarian endometriosis, its pathogenesis, associated and probable biomarkers, cases of malignant transformation, principles of diagnosis and treatment.

Despite intensive research of endometriosis even at the molecular level, its origin, natural history, malignant transformation, and laboratory management are not yet clearly investigated.

Early laboratory diagnoses of endometriosis, its atypical form, and possibility of transformation to endometriosis-associated ovarian cancers are important problems that require further study.

\section{INTRODUCTION}

Endometriosis is an important medical and social problem. It is the third most common factor in the pathogenesis of gynecologic diseases after inflammatory processes and uterine leiomyoma. Previous studies have shown that its incidence in fertile women ranges from 10\% to $50 \%$. It is one of the most frequent causes of reproductive malfunction, concomitant infertility, and chronic pelvic pain syndrome development [1]. About $80 \%$ of women suffering from chronic pelvic pain and up to $50 \%$ of women with diverse forms of infertility have been shown to have endometriosis. Ovarian endometriosis and adenomyosis can result in infertility and is second in frequency after inflammatory processes of the female genital tract, making up from $37 \%$ to $50 \%$ of such observations [1]. Endometriosis is an estrogendependent gynecologic disease, and it rarely appears before menarche or after menopause. The stabilization or regression of endometriosis could be observed during pregnancy or medical treatment for amenorrhea [1]. The classical role of estrogen and the great importance of paracrine and autocrine mechanisms are well established [1-4]. Importantly, endometriosis is a known risk factor for ovarian cancer [5] and can transform to atypical form and even undergo malignant transformation in $0.7-2.5 \%$ of cases [6, 7]. All electronic searches were conducted on four different electronic databases (MEDLINE, Scopus, Embase, and PubMed) to retrieve relevant studies conducted over the last 30 years. The search terms used were as follows: "endometriosis," "biomarkers", "endometriosis pathogenesis", "endometriosis-associated tumors", "treatment of endometriosis".

The aim of this review is to summarize the information in modern literature about the complexity of pathogenesis of endometriosis, its ability to undergo malignant transformation, possible biomarkers that can be used in early diagnostics, and principles of treatment. This article is based on previously conducted studies and does not contain any studies with human participants or animals performed by any of the authors.

\section{COMPLEXITY OF THE PATHOGENESIS OF ENDOMETRIOSIS}

More than ten theories on the origin of endometriosis have been proposed, each of which offers an explanation of its etiology, pathogenesis, and pathological process; but no one theory explains all of the various forms and manifestations of this disease $[1,2,8-10]$. These 
theories include diverse factors such as retrograde menstruation, altered immune response, coelomic metaplasia, embryonic rest theory, lymphovascular metastasis, molecular alterations, genetic instability, etc. (Figs. 1 and 2).

The most quoted two theories of endometrial implantation assume either that endometrial cells reflux or that retrograde menstruation involving the fallopian tubes results in implantation and proliferation elsewhere [6-8]. While both theories are plausible, they have weaknesses. The implantation theory cannot explain the development of endometriosis in
$10-15 \%$ of women. The reflux theory of endometrial tissue dispersing through the fallopian tubes during menstrual periods is an almost universal phenomenon, but it fails to explain the admittedly rare cases of endometriosis when the menstrual uterus is absent [8-10].

According to the coelomic metaplasia theory, endometriosis arises from mesothelial cells on the ovarian surfaces that are transformed into endometriotic gland cells. This theory supports the rare cases of endometriosis among men and pubertal girls [11].

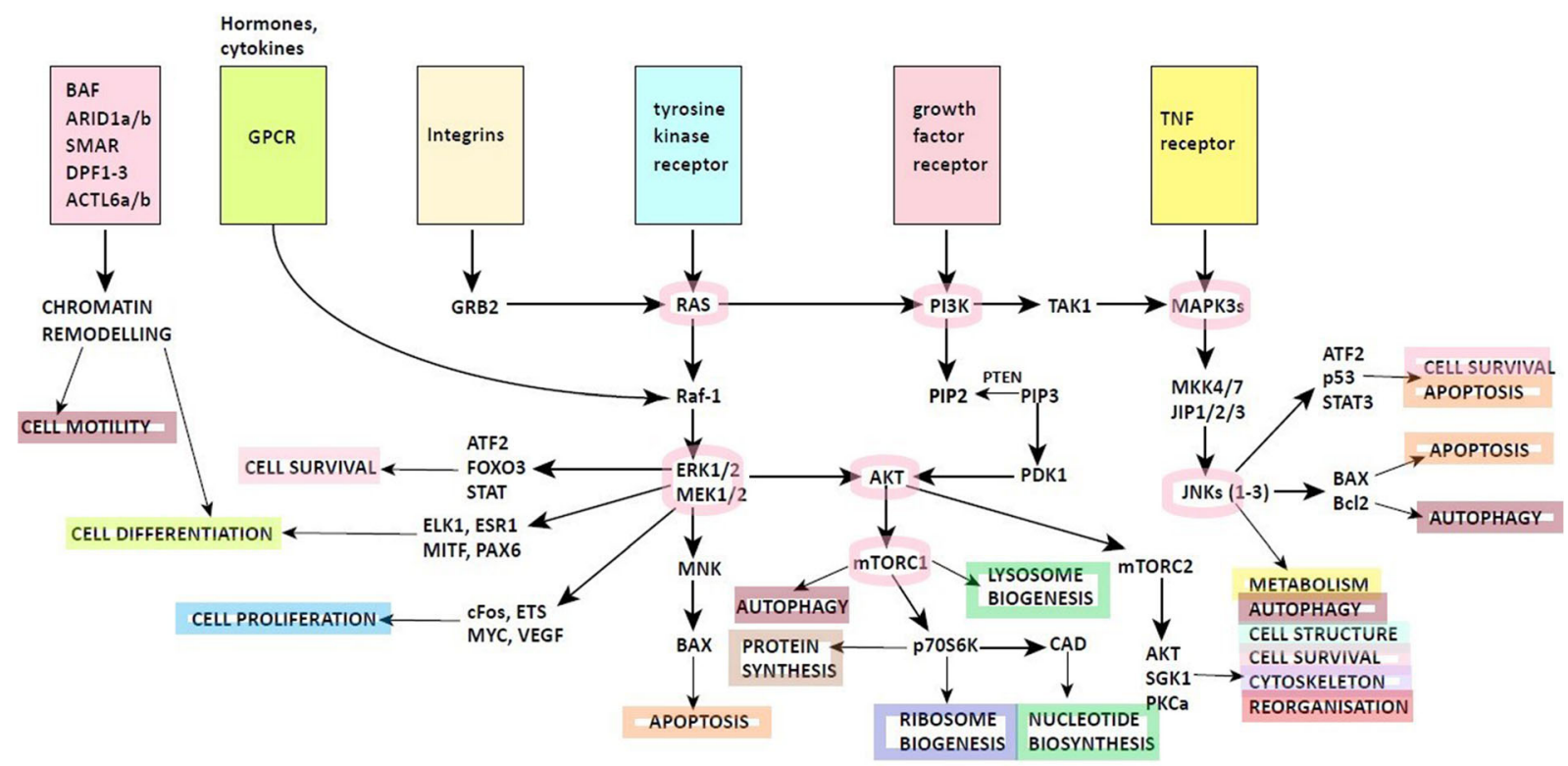

Fig. 1 Possible molecular mechanisms in endometriotic cells proliferation, survival, and progression towards malignancy. BAF BRM-associated factor, ARID1a/b ATrich interactive domain-containing protein $1 \mathrm{~A} / \mathrm{B}$, SMAR scaffold/matrix attachment region-binding protein 1 , DPF1-3 zinc and double PHD fingers family 1 protein, ACTL6a/b actin-like protein 6A/B, GPCR G-proteincoupled receptors, GRB2 growth factor receptor-bound protein 2, RAS protein superfamily of small GTPases, Raf1 proto-oncogene serine/threonine-protein kinase, TNF tumor necrosis factor, PI3K phosphoinositide 3-kinases, TAK1 mitogen-activated protein kinase kinase kinase 7 , MAPK3 and ERK1/2 mitogen-activated protein kinase 3/ 2, MKK 4/7 dual-specificity mitogen-activated protein kinase kinase 4/7, JIP1/2/3 JNK-interacting protein 1/2/ 3, JNKs(1-3) c-Jun $\mathrm{N}$-terminal kinases (1-3), ATF2 activating transcription factor $2, \mathrm{p} 53$ tumor protein $\mathrm{p} 53$, STAT3 signal transducer and activator of transcription 3,
BAX Bcl-2-like protein 4, Bcl-2 B cell lymphoma 2, AKT protein kinase $\mathrm{B}, \mathrm{FOXO} 3$ forkhead box O3, MEK1/2 mitogen-activated protein kinase kinase 1/2, ELK1 ETS like-1 protein Elk-1, ESR1 estrogen receptor 1, MITF microphthalmia-associated transcription factor, PAX6 paired box protein, cFos proto-oncogene, member of a bigger Fos family of transcription factors, ETS erythroblast transformation specific member, MYC MYC proto-oncogene, VEGF vascular endothelial growth factor, MNK mitogen-activated kinase, mTORC1/2 mammalian target of rapamycin complex 1/2, p7056K ribosomal protein S6 kinase beta-1, CAD carbamoyl-phosphate synthetase 2, SGK1 serum and glucocorticoid-regulated kinase 1, PKC protein kinase C, PTEN phosphatase and tensin homolog, PIP 2/3 phosphatidylinositol 4,5-bisphosphate/trisphosphate, PDK1 pyruvate dehydrogenase lipoamide kinase isozyme 1 


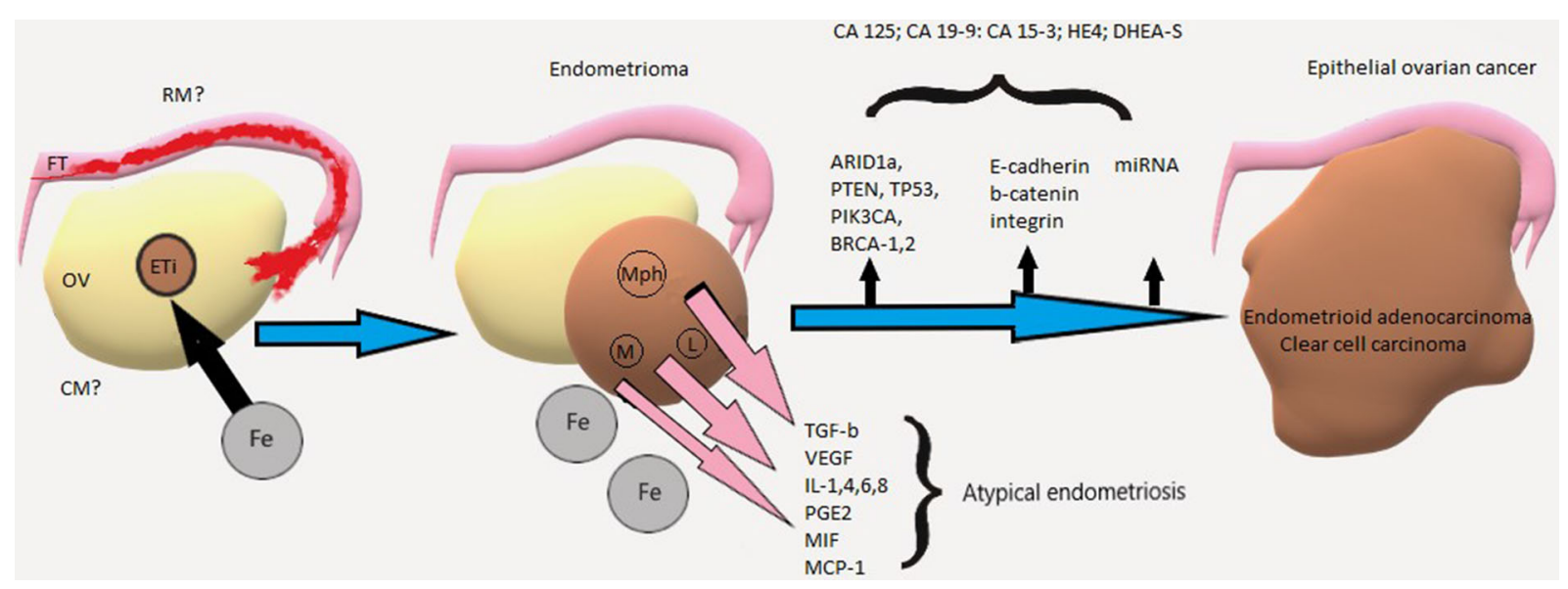

Fig. 2 Pathogenesis and progression of endometriosis. OV ovary, FT fallopian tube, RM retrograde menstruation, CM coelomic metaplasia, ETi endometriotic tissue, Fe iron, Mph macrophage, M monocytes, L lymphocytes

Embryonic rest theory proposes that some endometrial cells may develop in the abdomen cavity during embryogenesis [12]. The fetal system controls and directs embryogenesis, but the mechanism is not fully understood. Abnormalities of this control system may give rise to detectable abnormalities of the adult immune system [13]. In turn, these abnormalities may control the degree of "aggressiveness" of the endometriosis and may result in different clinical behavior of endometriosis [14, 15].

There is a new unifying theory that endometriosis is the result of endometrial stem cells that migrate and proliferate during embryogenesis [16]. This theory is based on finding small focuses with glands and stroma in female fetuses in the cul-de-sac of the peritoneum that are supposed to be the remnants or the result of metaplasia of the Müllerian system. These remnants may contain endometrial stem cells that can produce endometriotic foci [16]. Interestingly, endometrial stem cells differ from bone marrow stem cells by overexpression of immune-function related gene pathways [16].

\section{DEVELOPMENTAL FACTORS}

Endometriosis means the presence of ectopic tissue that is similar to an endometrium with glands and stroma. The endometria of women with endometriosis may have abnormal features in comparison to the endometria of healthy women $[8,9]$. The abnormal endometrium may be able to protect itself from destruction by the immune system by expressing specific antigens through the accumulation of various populations of immune cells, as well as synthesis and secretion of immunosuppressive factors $[8,9,17]$. There are several characteristic features of the endometrium in the case of endometriosis, including:

(a) Production of its own estrogen in a large amount $[8,9,15]$.

(b) Implantation into the peritoneum $[15,17,18]$.

(c) Proliferation and invasion into surrounding tissues $[15,17,18]$.

(d) Aggressive growth and adhesion in the peritoneum $[15,17,18]$.

(e) Self-defense from physiological apoptosis $[15,17,18]$.

(f) Pathological expression of heat shock proteins and excessive angiogenesis $[4,8,9,17,18]$.

Additional theories propose that the immune system must be compromised to allow the ectopic endometriotic tissue to grow [13]. Endometriosis is associated with inflammation, so macrophages play a key role in its development: they are found in endometrioma walls, peritoneal fluids, and other ectopic foci. Macrophages secrete many products such as tumor growth factor- $\beta$ (TGF $\beta)$, vascular endothelial growth factor (VEGF), interleukin-1 (IL-1), 
prostaglandin $\mathrm{E}_{2} \quad\left(\mathrm{PGE}_{2}\right)$, and macrophage migration inhibitory factor (MIF). Activated macrophages can enhance oxidative stress conditions via the production of lipid peroxides and other by-products of the reaction between apolipoproteins and peroxides [19]. The result of these events is the accretion of the pro-inflammatory mediators, leading to inflammation in women with endometriosis [19]. TGF $\beta$ plays a significant role in increasing the rate of postsurgical adhesion formation [20]. Experimental murine models show that macrophage activation after endometrial tissue implantation increases secretion of VEGF [21]. IL-1 is a macrophage-derived cytokine inducing the expression of cyclooxygenase-2 (COX-2) and interleukin-8 (IL-8) to facilitate migration, proliferation, and angiogenesis in endometriotic tissue [22]. $\mathrm{PGE}_{2}$ affects the leukocyte population and promotes angiogenesis via its effect on estrogen and VEGF upregulation [23]. It inhibits apoptosis and upregulates fibroblast growth factor 9 (FGF9) to promote cell proliferation as well [13].

Endometriotic lesion cells show increased adhesive capability to extracellular matrix components, such as collagen type IV, laminin, vitronectin, and fibronectin [20, 24]. Endometriosis is associated with aberrant expression of E-cadherin, $\beta$-catenin, and integrins. Integrins are a group of cell-to-cell adhesion molecules and enforce cell attachment to the extracellular matrix proteins, thereby providing cell migration and invasiveness [25]. Of note, $\beta$-catenin is an important molecule in cellto-cell adhesion and intracellular signaling that binds to intracellular E-cadherin and connects E-cadherin to the cell cytoskeleton [26]. The E-cadherin- $\beta$-catenin complex plays a crucial role in epithelial cell-cell adhesion and in the tissue architecture [27]. Cancer initiation and progression affect aberrant expression of cadherins and integrins [28]. Controversial reports have been published describing the expression levels of these adhesion proteins in the case of endometriosis. In keeping with this, $\beta$-catenin expression may be involved in the pathogenesis of endometriosis via increasing expression of $\beta$ catenin and activation of the Wingless Int-1 (Wnt)/ $\beta$-catenin complex $[27,29,30]$.
Endometriosis showed decreasing $\beta$-catenin expression in comparison to ovarian endometrioid carcinoma. This fact reflects that the pathogeneses of endometriosis and endometrioid carcinoma have different alterations in the E-cadherin- $\beta$-catenin complex [13]. Thereby different epithelial adhesion molecules are involved in the initiation and progression of benign endometrioid lesions [25]. Wnt/ $\beta$-catenin complex plays a pivotal role in stem cell regulation and cell development by merging signals from other pathways, such as TGF $\beta$ and FGF. This complex also targets cell migration and proliferation genes [31]. TGF $\beta$ provides migration and proliferation of fibroblasts in ovarian endometriotic lesions [29]. Loss of E-cadherin expression may be connected to the aggressive behavior and invasive growth of peritoneal endometriotic lesions $[27,32]$. E-cadherin expression in endometrial cells has been reported to be constant throughout the menstrual cycle [32, 33]. However, another study found that E-cadherin mRNA was significantly lower in the proliferative phase than in the secretory phase [34]. Thus, E-cadherin expression may be dependent on the phase of menstrual cycle and stage of endometriosis. Moreover, E-cadherin expression patterns in endometriotic tissues are contradictory; therefore, the role of E-cadherin in the development and progression of endometriosis remains unclear [13].

MicroRNAs (miRNAs) are small non-coding RNA molecules containing about 22 nucleotides that are found in plants, animals, and some viruses and provide post-transcriptional regulation of gene expression [35]. miRNAs take part in several biological processes including cell proliferation, differentiation, and apoptosis. Epigenetic regulation by miRNAs plays an important role in endometriosis development supported by the fact of differential expression of miRNAs in endometriosis tissues compared to normal endometrium [36-38]. Target gene recognition can be complicated by single nucleotide polymorphisms within miRNA binding sites. This means that single nucleotide polymorphisms within or near a miRNA target site may serve as an epigenetic modulator of endometriosis predisposition and may explain 
familial and twin cases that suggest endometriosis is inherited in a polygenic manner [39-41]. However, these studies have shown limited consistency or conflicting results, and no miRNA-based diagnostic test has been validated in an independent patient cohort [42].

Bone morphogenetic protein receptor type1B (BMPR1B) is a transmembrane receptor mediating TGF $\beta$ signal transduction and has been shown to be a tumor suppressor in ovarian cancer. Endometriosis and ovarian cancer glycosylation-associated biomarker CA125 (carbohydrate antigen 125) inversely correlated with BMPR1B in endometrial cells. Polymorphism at BMPR $1 B$ 3'UTR in the miR-125b binding site violates its affinity toward the miRNA, which may result in insufficient post-transcriptional repression. Genetic variations in the mir-125b seed region reduces suppressive effect of mir$125 \mathrm{~b}$ and result in upregulation of BMPR1B. Elevated BMPR1B levels in endometrial cells have been shown to reduce cell proliferation and migration activity by downregulation of IL$1 \beta$, reflecting a lower risk for endometriosis [43].

\section{BIOMARKERS ASSOCIATED WITH ENDOMETRIOSIS}

A study by Gupta et al. [44] with 2729 participants studied the proteome, finding that $17 \beta$ hydroxysteroid dehydrogenase 2 (17 $\beta$ HSD2), IL1R2, caldesmon, and other neural markers (vasoactive intestinal peptide (VIP), calcitonin generelated peptide (CGRP), substance $P$ (SP), neuropeptide Y (NPY), and a combination of VIP, PGP 9.5, and SP) have the promising ability to diagnose endometriosis accurately. Laparoscopy has been the gold standard for diagnosis of endometriosis and, today, non-invasive methods may be used only for research purposes $[44,45]$. Nevertheless, it was shown that there is a correlations between CA125 and carbohydrate antigen 19-9 (CA19-9) and dehydroepiandrosterone sulfate (DHEA-S) $(R=0.52$ and $R=0.49)$. This initial result reflects that androgen-dependent increases in CA125 and CA19-9 levels are potentially significant diagnostic biomarkers of endometrial pathology [46].
The diagnosis of peritoneal endometriosis relies on a visual inspection using laparoscopy followed by histological confirmation [47]. Great efforts have been made to find non- or semi-invasive tests for diagnosis of endometriosis. The most important goal of these tests is to identify $100 \%$ of woman with endometriosis or other significant pelvic pathology who could form clinical groups that might benefit from surgery for endometriosisassociated pain or infertility [48-50]. A non-invasive diagnostic test could be developed for serum or plasma, urine, endometrial fluid, or menstrual fluid that can be recovered from the posterior vaginal fornix and from the cervix during speculum examination. A semi-invasive test could be developed using peritoneal fluid obtained after transvaginal ultrasound-guided aspiration or in the endometrium obtained after transcervical endometrial biopsy [48, 49]. Based on these findings, there is a need to develop a sensitive diagnostic test for endometriosis because of the unavailability of a current valid test $[48,51,52]$.

There is consensus in the World Endometriosis Society that the development of a reliable, non-invasive test is one of the top research priorities in endometriosis [53, 54]. The development of such a test extending from initial biomarker discovery to a clinically approved biomarker assay is a difficult, timeconsuming process $[52,54]$.

Overall, most studies of endometriosis biomarkers have remained at the level of exploratory preclinical studies aimed to identify potential biomarkers [51]. Only a few effectively passed the preclinical development and validation of a clinically useful non-invasive diagnostic test. A clinically reliable test for endometriosis is expected to have a profound impact on reduction of health care and individual costs by reducing expensive hit-and-miss treatments $[49,55]$. Taken together, a non- or semi-invasive test would not only reduce the costs associated with endometriosis diagnosis but also improve the quality of life in women with endometriosis by enabling early diagnosis and treatment.

Blood is an important source of biomarkers because it allows repeated measurements, is 
easily obtained, and is highly suitable for highthroughput measurements [56]. Endometriosis biomarkers are mainly glycoproteins, growth or adhesion factors, hormones, or proteins related to immunology or angiogenesis [48, 57, 58]. Unfortunately, neither a single biomarker nor a panel of biomarkers found in peripheral blood has been validated as a diagnostic test for endometriosis $[48,51]$.

\section{GLYCOSYLATION-ASSOCIATED BIOMARKERS}

Cancer disease markers of disturbed glycosylation lead to production of tumor-associated glycans and glycoproteins. These molecules are consistently secreted or ejected together with a cell membrane into the bloodstream and, thereby, can serve as tumor markers. An increase in glycosylation in tumor cells is started by means of excessive expression of glycoproteins that contain certain specific glycans, increase or decrease in nucleotide sugars donors, and disturbances in glycosyltransferase and the glycosidase enzymes expression. These markers of glycosylation applied to the detection and monitoring of tumors include CA125, CA19-9, carcinoembryonic antigen (CEA), prostate-specific antigen (PSA), and alfa-fetoprotein (AFP). Owing to their specific affinity for certain parts of sugars, lectins are useful for studying development and identification of these tumor-associated glycans and glycoproteins in clinical practice. Accordingly, various enzyme-binding lectin assays (ELLA) were developed for diagnostics, monitoring, and prognosis. As glycosylation changes occur in the early stages of tumors, the tumor-associated lectin-based glycosylation markers become an effective strategy to improve diagnosis and treatment follow-up [59].

CA125 is an antigen-determined highmolecular weight glycoprotein distinguished by a mouse monoclonal antibody OC125. It contains two main antigenic domains classified as A, the OC125 monoclonal antibody binding domain, and B, the M11 monoclonal antibody binding domain. CA125 is expressed by amniotic and coelomic epithelium during gestation.
It has been found in adults in the structures that develop from coelomic epithelium (mesothelial cells of pleura, pericardium, and peritoneum) in tubal, endometrial, and endocervical epithelia. It is intriguing that the superficial epithelium of normal ovaries of fetuses and adults do not express it, except for cases of inclusion cysts or areas of metaplasia and papillary growths. Serum CA125 was defined initially by means of homologous assay based on only the usage of OS125 monoclonal antibody. This research was replaced by a heterologous one, using OS125 as a capturing antibody, and M11 as a detecting antibody. Now, there are different techniques for CA125 analysis that are clinically reliable and well correlated [60]. The level $35 \mathrm{IU} / \mathrm{ml}$ in serum obtained in $1 \%$ of healthy female donors is often assumed as the normal upper level in clinical practice. However, this level is disputable and cannot ideally correspond to all CA125 values. For example, in postmenopausal women or in patients after a hysterectomy, CA125 level tends to decrease compared to the general population (20 and $26 \mathrm{IU} / \mathrm{ml}$ ) [61]. In general, about $85 \%$ of patients with ovarian epithelial tumors have CA125 levels higher than $35 \mathrm{IU} / \mathrm{ml}$. Levels above $35 \mathrm{IU} / \mathrm{ml}$ were found in $50 \%$ of patients with stage I ovarian tumor while higher serum CA125 levels were found in more than $90 \%$ of women at more advanced stages $[60,61]$. CA125 rises in mucinous, clear cell, and borderline tumors less often than in malignant ones. Increase in serum CA125 can be associated with other malignant tumors (pancreas, breast, large intestine, and lung) as well as benign and physiological conditions including pregnancy, endometriosis, and periods [62]. The majority of these nonmalignant conditions are not found in postmenopausal women, which improves the diagnostic accuracy [4, 60, 63].

Many authors consider CA125 to be an endometriosis marker and believe that CA125 concentration $\geq 30 \mathrm{IU} / \mathrm{ml}$ is an endometriosis indicator with high precision in women with symptoms of pain and infertility. If endometriosis is suspected, CA125 should be considered as a diagnostic test, in which the concentration CA125 is $<30 \mathrm{IU} / \mathrm{ml}$. 
Nevertheless, it cannot be assumed to reveal endometriosis by itself $[4,63-66]$.

Another ovarian tumor marker, CA19-9, is elevated in endometriosis and has a comparable or lower sensitivity than CA125 for the detection of endometriosis [51]. A recent study showed a significant increase of CA125 $(p=0.001)$, CA19-9 $(p=0.015)$, and CA15-3 $(p=0.017)$ in endometriosis cases $(n=50)$ versus controls $(n=35)$. Receiver operating characteristic (ROC) curve analysis showed that the area under the curve was the highest for CA125 (0.938). A significant positive correlation with disease severity was found for CA19-9 as well [67].

\section{INFLAMMATION-ASSOCIATED BIOMARKERS}

Inflammatory markers have been implicated in the pathogenesis of endometriosis. Many cytokines have been examined as possible biomarkers for endometriosis such as IL-1, IL-6, IL-8, tumor necrosis factor- $\alpha$ (TNF $\alpha$ ), monocyte chemoattractant protein 1 (MCP-1), and interferon- $\gamma$ (INF $\gamma$ ) [51]. Endometriosis has been shown to be associated with impaired $\mathrm{T}$ cell function. Thus, helper $\mathrm{T}$ cells produce cytokine IL-4 that is significantly upregulated in endometriotic lesions and intensifies endometriotic cell proliferation [68]. Peritoneal fluid of women with endometriosis contains a number of Th17 cells as in the ectopic endometrium. IL-17 stimulates IL-8 and COX-2 expression and enhances proliferation and migration of endometriotic cells [69]. MCP-1 is a member of the small inducible gene family that plays a role in the recruitment of monocytes to injury and inflammation sites [70]. MCP-1 level is elevated in the peritoneal fluid and serum of women with endometriosis, in particular in early stages [71].

\section{BLOOD/CYCLE-ASSOCIATED FACTORS}

Iron is an essential element for many processes carried out within the cell. Abnormal iron regulation due to iron overload is destructive [72]. A large majority of iron (i.e., $3-5 \mathrm{~g}$ ) in humans is contained in hemoglobin and the remainder is stored in protein complex ferritin in hepatocytes and macrophages [73]. In the case of iron deficiency, iron can be released from ferritin by ferritinophagy, which is an autophagic process [74]. Iron supports important intracellular processes such as oxygen transport, metabolism, and DNA synthesis [75].

Retrograde menstruation is one of the pathogenetic theories of endometriosis development and subsequent transformation to rare types of ovarian cancers including endometrioid and clear cell ovarian carcinomas [76]. The pelvic cavity may have an elevated iron level due to retrograde menstruation, which may promote desquamated endometrial cell survival and implantation at ectopic sites [77]. Iron deposits (e.g., hemosiderin) have been revealed in endometriotic ovarian lesions as well as in the fallopian tubes of patients diagnosed with serous epithelial ovarian carcinomas [78, 79].

Follicular fluid is considered a potential contributor to ovarian cancer pathogenesis [80]. It is well known that follicular fluid contains active hormones such as estradiol [80], reactive oxygen species, and transferrin [81]. Increased levels of iron and DNA adducts were founded in follicular fluid of patients with endometriosis compared to infertile controls $[82,83]$. Iron and transcript levels of ferritin and transferrin receptors were increased in follicles settled nearby to an endometrioid ovarian cyst affecting oocyte maturation [84]. Nevertheless another study did not find any differences in iron or ferritin contents [85]. Small increases in cell proliferation and in IL-8 cytokine levels are observed after contact with fallopian epithelium and follicular fluids [86]. Follicular fluids containing high levels of reactive oxygen species are capable of inducing early-onset B cell lymphoma in mammary fat pads in mice lacking tumor protein p53 [87]. Some experiments show that fimbrial epithelial cells exposed to increasing doses of iron revealed an increase in cellular proliferation and changes in p53, mitogen-activated protein kinase (MAPK), serine-threonine protein kinase (AKT), c-Myc proteins, and reactive oxygen species 
(0.05-100 mM) [88]. These oxidative stress-induced events mediated by iron were opposed by vitamin $\mathrm{D}_{3}$ [89]. It is notable that a clear cell ovarian cancer gene signature was induced upon iron exposure in immortalized ovarian surface epithelial cells that support the transition from precursor cells to cancer [90].

\section{GENES INVOLVED IN ENDOMETRIOSIS DEVELOPMENT}

The gene network of endometriosis includes genes of hormones and their receptors, tumor suppressors, the detoxification systems, cytokines, and their receptors, embryonic development and cell proliferation, and others, involved in more than 30 metabolic ways (Fig. 1) [91]. Epigenetic factors (e.g., level of DNA methylation, modification of histone proteins, microRNA) are important in the development of endometriosis [92].

Somatic mutations and other genomic aberrations have been found in endometriosis that have been implicated in the development of cancer. Mutations in Kirsten rat sarcoma (KRAS) [93, 94], tumor protein p53 gene (TP53) $[95,96]$, phosphatidylinositol-4,5-bisphosphate 3-kinase (PIK3CA) [97, 98], phosphatase and tensin homolog (PTEN) [99], and AT-rich interactive domain-containing protein $1 \mathrm{~A}$ (ARID1A) gene regions [100, 101] have been described. Microsatellite instability [102], loss of expression of mismatch repair enzymes [103], and tissue-specific gene copy-number changes $[104,105]$ may also be seen in endometriosis lesions. Loss of heterozygosity resulting in PTEN loss may be an early driver event in the genesis of endometriosis-associated ovarian carcinomas arising from endometriosis [99, 106]. Over the last 7 years, sequencing and immunohistochemical studies have revealed that mutations found in endometriosis-associated cancers are found in adjacent endometriosis [107]. These sequencing studies clearly demonstrate a clonal relationship between benign and malignant counterparts confirming that the cancers have arisen from the endometriotic lesions [100, 101, 108, 109].

\section{KRAS}

RAS proteins include $\mathrm{H}-, \mathrm{K}-$ and N-RAS, closely related members that activate a wide array of downstream signaling pathways with a multitude of effector proteins, including Raf/ERK and PI3K/AKT [110]. Extracellular signal-regulated kinases (ERK1/2) has several substrates, including epidermal growth factor (EGF) and estrogen receptors (ERs) [110]. They function as intracellular switches in signal transduction cascades that regulate proliferation, apoptosis, and differentiation [111].

Oncogenic KRAS is encoded by the KRAS-2 gene [112], is downstream of epidermal growth factor receptor (EGFR), and is an essential component of the EGFR signaling cascade [113]. It is frequently mutated in various malignancies, such as colorectal cancer (ca. $40 \%$ ), lung cancer (ca. 25\%), and pancreatic cancer (ca. 90\%) [114, 115]. EGFR inhibitors become ineffective as a result of the impact of $K R A S$ mutation on the EGFR pathway [116]. $K R A S$ also can be activated by angiotensin II [117], endothelin-1 [118], TGF $\beta 1$ [119], plateletderived growth factor (PDGF) [120], EGF [121], and thrombin [122]. These genes/molecules or their receptors (e.g., angiotensin II receptors AT-1 and AT-2) are all reported to be overexpressed/elevated in endometriosis [123-127].

KRAS mutation attracted much attention after the report that the activation of a KRAS allele resulted in peritoneal endometriosis in mice [128]. In this model the onset of endometriosis appeared to be quite late (ca. 8 months after conditional induction of $K R A S$ ) [128], which raises the question as to whether this mouse model of endometriosis truly recapitulates the human counterpart. Indeed, KRASactivating mutation is reported to be rare in endometriomas [90], even though elevated KRAS expression in eutopic endometrium in women with endometriosis has been reported [129-131]. The prolonged latency period in inducing endometriosis suggests that the KRAS mutation alone may not be sufficient to induce endometriosis. The mouse model of endometriosis also shows that the growth of 
lesions is ER-dependent since estrogen antagonism suppresses the lesion growth [132]. Consistent with this, the lesions exhibit fibrosis as seen by marked collagen deposition [132].

KRAS mutations have been identified in 12 (29\%) of 42 endometriosis-associated ovarian low-grade endometrioid adenocarcinomas [133]. Inactivating mutation has recently been reported in deep endometriosis lesions [93]. Additionally, membrane-type matrix metalloproteinase (MT1-MMP) expression has been consistently documented to be elevated in ectopic endometrium [134] and in peritoneal fluid [135] and eutopic endometrium [136] from women with endometriosis. Thus, KRAS mutation is possible in endometriosis, but it seems to be rarely activated [107].

\section{ARID1A}

$A R I D 1 A$ is the tumor suppressor encoding protein BAF250 of the switch/sucrose non-fermentable (SWI-SNF-A) complex participating in chromatin remodeling. The somatic inactivating mutation of a gene of ARID1A and loss of expression of BAF250a is an early disturbance at endometrioid carcinoma of ovaries that belongs to a group endometriosis-associated carcinomas [137]. About $42-61 \%$ of clear cell carcinomas and $21-33 \%$ of endometrioid carcinomas show loss of the ARID1A gene protein expression (BAF250a) on immunohistochemistry (IHC) [101, 108, 138]. ARID1A regulates proliferation and genomic stability as a tumor suppressor gene; therefore, it was thought that it may play a role in the transformation of endometriosis to cancer [139]. Similar mutations in PIK3CA were detected between endometriosis and clear cell tumors, occurring in early progression mechanisms in other cancer types [100]. Multifocal benign endometriotic lesions are related clonally, and clear cell carcinomas arising in these patients progress from endometriotic lesions that may already carry sufficient cancer-associated mutations to be considered neoplasms themselves but with low malignant potential [100].

Studies examining BAF250a expression by IHC have shown that in just over half of the reported cases of endometriosis-associated tumors, loss of BAF250a expression is seen in $67-80 \%$ in areas of contiguous endometriosis or atypical endometriosis. A loss of BAF250a protein expression seems to be an early molecular event in the development of BAF250a-negative endometriosis-associated tumors [108, 109, 140].

Interestingly, ARID1A mutations are not sufficient on their own to cause cancer [141]. An important study recently reported that $65 \%$ of cancer-causing genomic aberrations are random DNA repair abnormalities [142]. Taking this information into context, one can conclude that BAF250a loss in endometriosis could represent endometriosis-associated tumor-precursor lesions; however, ARID1A mutations are neither a necessary driver for mutation nor a sufficient determinant of the malignant phenotype. The presence of mutations in endometriosis may be a sign of broader genomic disruption leading to the development of endometriosis-associated tumors. Studies have been done comparing patient outcomes in cases of endometriosis-associated tumors based on the presence or absence of BAF250a expression: the presence or absence of an endometriosis precursor lesion in endometriosis-associated tumors has not been associated with a change in overall disease outcome [143].

\section{PI3K/AKT PATHWAY}

Presence of classical oncogene mutations in ovarian endometriosis was revealed initially in 2018: a combination of mutations of KRAS and ARID1A was identified in some patients that led to the preliminary conclusion that endometriosis is a precancerous disease [144]. It was discovered that activation of PI3K/AKT leads to changes in the family of proteins forkhead box protein O1 (FOXO1) influencing through the insulin-like growth factor-binding protein 1 (IGFBP1) and developing resistance to progesterone in endometriosis. High levels of AKT and nuclear proteins of FOXO1 and IGFBP1 were evident in ectopic atypical endometrial foci. These data may demonstrate that the PI3K/ AKT pathway participates in the processes of 
hormone resistance in endometriosis. This activating mutation is identified in more than $40 \%$ of observations in endometriosis-associated ovarian cancer [145]. PIK3CA exons 9 and 20 were sequenced in 23 samples of clear cell ovarian cancer and activating mutations were found in $43 \%$ of samples-H1047R. The same mutation was revealed in atypical endometriosis in $90 \%$ of observations. In this regard, the assumption was made that such mutations arise early enough that carrying out such analyses for oncological prevention is advantageous in infiltrative forms of endometriosis [145].

PTEN, or phosphatase and tensin homolog deleted on chromosome 10, is a tumor suppressor through regulation of proliferation and survival [146]. It is the second most frequently mutated gene in human cancers after TP53, but the mutation spectrums of PTEN and TP53 are different [146]. PTEN inhibits PI3K/AKT signaling by converting phosphatidylinositol $(3,4,5)$ trisphosphate (PIP3) to phosphatidylinositol 4,5-bisphosphate (PIP2) [146]. Of particular interest to endometriosis is its ability to maintain genomic stability [147-149]. In endometriosis, the first attempt to evaluate PTEN mutation yielded negative results [150], but another study reported a mutation frequency of $21 \%(7 / 34)$ in endometriomas [99]. One study found no mutation at PTEN (0/23) [94], but the negative finding may be attributable to a lack of adequate statistical power due to a small sample size. PTEN loss and loss of heterozygosity have been reported in endometriosis malignant transformation [151-153]. Conditional deletion of PTEN is found to induce endometriosis in mice [128]. Reduced PTEN expression has been reported in endometriosis [153-155]. 17 $\beta$-Estradiol promotes cell proliferation through activating PI3K/AKT and MAPK/ERK signaling pathways via an NF-кB/PTEN-dependent pathway in endometriotic epithelial cells [153]. IL-8 is also reported to enhance proliferation, reduce apoptosis in endometrial stromal cells through the upregulation of survivin and B cell lymphoma 2 (Bcl-2), inhibition of PTEN, and activation of AKT [156]. Consistently, AKT activation has been shown to promote the establishment of endometriosis [157]. PTEN overexpression suppresses cell proliferation, but enhances apoptosis and G1 cell cycle arrest in endometriotic epithelial cells [158].

\section{MTOR SIGNALING PATHWAY}

The mechanistic target of rapamycin (mTOR) is a highly conserved, atypical serine/threonineprotein kinase. It interacts with other proteins to form two multi-protein complexes: the mTOR complex mTORC1 and mTORC2. Both complexes contain target of rapamycin complex subunit LST8 (mLST8/GßL) and DEP domain-containing mTOR-interacting protein (DEPTOR). mTORC1 also contains regulatoryassociated protein of mTOR (Raptor) and proline-rich Akt substrate of $40 \mathrm{kDa}$ (PRAS40) proteins, wherein Raptor interacts with the target of rapamycin signaling (TOS) motifs of mTOR substrates in a rapamycin-sensitive manner to activate this complex. mTORC2 also contains rapamycin-insensitive companion of mammalian target of rapamycin (Rictor), target of rapamycin complex 2 subunit MAPKAP1 (mSIN1), and protein observed with rictor 1 and 2 (Protor1/2), and the functional activity of mTORC2 is dependent on Rictor and mSIN1. mTOR signaling can be activated by upstream signals including growth factors (e.g., insulin, insulin-like growth factor 1, IGF1), cellular stress, metabolism/energy state (e.g., $\mathrm{O}_{2}$ and ATP/ADP), amino acid nutrients (e.g., leucine and arginine), and neurotransmitters (e.g., neuropeptides and glutamate). mTOR signaling controls several fundamental biological processes including translation and turnover of proteins, lipid and glucose metabolism, cellular growth, proliferation, survival, autophagy, cytoskeleton organization, etc. Aberrant mTOR signaling has been linked to the pathophysiology of diseases like cancer, cardiovascular disorders, and diabetes.

\section{HOX AND WNT GENES}

Homeobox (Hox) genes plays an important role in mammal embryogenesis and provide the skeletal development, especially the head-tail 
axis. The Hox genes control the differentiation of cells, the segmental embryonic development, involved in malformations of the urogenital tract and their inactivation leads to complete absence of Müllerian structures [159, 160]. Thus, its absence leads to embryonal death and multiple organ system abnormalities. The clusters of Hox genes during development are subject to transcriptional control by cofactors such as retinoic acid (RA) [161], FGF [162], and the genes of the Wnt pathway [163]. Organogenesis of the female genital tract is regulated by homeobox transcription factors [164]: HoxA-9, HoxA-10, HoxA-11, and HoxA-13 [165]. These transcriptional factors interact with bone morphogenetic protein (BMP)-4, Wnt7a, b3-integrin, EGFB, and empty spiracles homeobox 2 (EMX2) gene and provide normal structures in the female genital tract. Wnt4 gene is an important factor in Müllerian duct formation [166]. Its malfunction can lead to anomalies of female genital organs and in endometrial glandular and stromal disintegration. Wnt7 is connected to HoxA-10 and HoxA-11 genes as mentioned above, and Wnt5 provides the distribution along the head-tail axis [167]. Wnt5a and Wnt7a are essential for normal endometrial glandular formation [168]. Three types of signaling pathways in female genital tract organogenesis were discovered: Wnt/b-catenin, Wnt/JNK (c-Jun N-terminal kinases), and Wnt/ $\mathrm{Ca} 2+$. Estrogen and its derivates may interfere with Wnt expression and/or b-catenin target genes with an alteration of the female genital organ development, and this fact is important in endometriosis formation [169]. The signaling pathway of Wnt genes and Wnt/b-catenin control different types of stem cells and can provide self-renewal of endometrial stem cells that can lead to future endometriotic foci growth $[170,171]$.

\section{ATYPICAL ENDOMETRIOSIS}

Endometriosis may be divided into peritoneal endometriosis, ovarian endometriosis or endometrioma, and deeply invasive endometriosis. Nowadays, increasing numbers of researchers are inclined to suggest that adenomyosis and endometriosis are separate diseases because of revealed essential morphologic, pathogenetic, molecular, and biological features [18]. Results of such research and clinical observations lead to differential approaches to clarify the pathogenesis of different clinical and morphological variants of endometriosis and to study the major pathogenetic factors (genetic, epigenetic, medical, and social) $[18,65]$. The existence of different clinical and morphological forms of endometriosis, depending on prevalence of the active and inactive endometrioid foci, is disputable [18]. It has been established that endometrioid heterotopic foci in ovaries are present in two morphologic variants simultaneously: one with endometrioid glands and the other with stromal cell growth and active neoangiogenesis. Endometrioid glands and stromal cell growth cause considerable remodeling of an ovary with expressed fibrosis that is followed by suppression of folliculogenesis accompanied by a decrease in fertility [18].

The atypical form of endometriosis is characterized by cellular atypia and excessive proliferation; however, it is difficult to establish the diagnosis of atypical endometriosis on the basis of only a morphological evaluation. Malignant transformation of endometriosis is a rare event that occurs approximately in $0.7-2.5 \%$ of cases and usually involves ovaries (Fig. 2). It was described that women with endometriosis have 2-3 times higher risk of developing of endometrioid and clear cell ovarian tumors [172]. Morphological research revealed the continuous process consisting of consecutive stages of change from normal epithelium in an endometrioid cyst to atypical endometriosis and, subsequently, to invasive carcinoma [173]. Epithelium of endometrioid cyst walls has syncytial papillary changes (39.7\%), metaplasia with hobnail cells (15.4\%), atypia of an epithelium with fluctuation of Ki-67 and Bcl-2 expression, with a low p53 expression in $41 \%$ of cases [137]. Hepatocyte nuclear factor 1 homeobox B (HNF-1 $\beta$ ) expression in the nuclei without atypia occurs in $56 \%$ of cases, and in the nuclei with atypia in 94\%, and is found only in clear cell adenocarcinomas [137]. The hyperexpression of HNF-1 $\beta$ allowed the 
adaptative nature and histogenetic connection between ovarian endometriosis and clear cell ovarian tumors.

The histological classification of ovarian tumors by the World Health Organization (WHO) is based on histogenetic principles. This classification categorizes ovarian tumors with regard to their derivation from epithelial cells, germ cells, and mesenchyme (the stroma and the sex cord). Epithelial ovarian tumors, which are the majority of malignant ovarian tumors, are further grouped into histological types as follows: serous, mucinous, seromucinous, endometrioid, clear cell, transitional cell tumors (Brenner tumors), carcinosarcoma, mixed epithelial tumor, undifferentiated carcinoma, and others [174]. Clear cell and endometrioid carcinomas are highly associated with endometriosis [175]. Endometriosis-associated ovary carcinomas develop from atypical endometriosis and have a special profile of molecular disturbances, such as mutations of genes of ARID1A, PTEN, and CTNNB1 (catenin beta 1). Endometriosis-associated cancers include clear cell and endometrioid ovarian carcinoma. A history of endometriosis has long been considered to be a risk factor for later development of these malignancies. Recent molecular genetic evidence has provided unequivocal evidence that these lesions are precursors for endometriosis-associated cancers [176].

Atypical endometriosis and ovarian endometriosis-associated tumors have common molecular damages, such as mutations of PTEN, $A R I D 1 A$, and hepatocyte nuclear factor- $1 \beta$ (HNF-1 $\beta$ ) upregulation. Moreover, mutations of ARID1A were noted in clear cell tumors and atypical endometriosis, but not in the remote endometrioid foci. Loss of BAF250a protein expression assumes the existence of ARID1A mutation and is a useful early marker of endometriosis malignant transformation [174, 175]. Besides, CTNNB1 mutations in 16-53.3\%, PTEN mutations in 14-20\%, and ARID1A mutations in $30-55 \%$ of cases were found in ovarian endometrioid adenocarcinoma. PIK3CA mutations in $20-40 \%$ and ARID1A mutations in $46-57 \%$ of cases are found in ovarian clear cell carcinoma [174]. While estrogen and progesterone receptors practically always are absent, HNF-1 $\beta$ often shows hyperexpression in this histological type $[177,178]$.

The developmental mechanism of endometriosis-associated ovarian cancers remains unknown. They can evolve via molecular transformation of endometriosis or be due to endometriotic tumor microenvironment activity. Additionally, the fact that the presence of endometriosis improves prognosis is undefined, but likely depends on the endometriotic microenvironment. The unique microenvironment in endometriosis lesions contains epithelial, stromal, and immune cells, which adapt to survive in hypoxic conditions with high levels of iron, estrogen, and inflammatory cytokines and chemokines. Investigation of the unique molecular features of the endometriotic microenvironment is important in precision therapies or prevention design, but the rarity of well-characterized clinical samples and the limited model systems are challenging obstacles [179]. According to the reviewed studies, there is a reasonable research hypothesis that different types of endometriosis or endometriosisassociated tumors [180] are different phenotypes of the same genetic changes [181].

\section{PRINCIPLES BEHIND TREATMENT}

The clinical diagnosis of endometriosis may be challenging because signs and symptoms may overlap with another gynecologic pathologies, even with cancer. The situation is aggravated by a lack of reliable diagnostic serum biomarkers [182]. Elevated levels of the biomarker CA125 are not specific and can indicate the presence of endometriosis, ovarian cancers, or inflammation [183]. Levels of the serum biomarker HE4 (human epididymis protein 4) is considered to be promising in distinguishing endometriosis from ovarian cancers, but its role is controversial in different conditions [184]. Endometriosis is suspected clinically in the majority of patients on the basis mainly of history and ultrasound examination and treated empirically with hormonal therapy (e.g., estrogen-progestin contraceptives or progestin-only therapies) without surgery [185]. Therefore, on the basis of the 
current situation, there is a need for a reliable diagnostic serum biomarker for clinically diagnosing endometriosis [186].

Surgical treatment with intraoperative frozen section analysis and subsequent histological examination of excised tissue remains the gold standard for diagnosis of any type of adnexal mass including endometriosis [186, 187]. Surgery generally is indicated for patients who are resistant to medical therapy or who are planning pregnancy. Laparoscopy is the typical approach [53, 188-191]. Robotic single-site surgery and single-port laparoendoscopic surgery can be used for the treatment of advancedstage endometriosis without any differences in outcome [192].

One of the most common complications of endometriosis surgery is diminished ovarian reserve with subsequent iatrogenic infertility $[193,194]$. There are several surgical techniques to treat ovarian endometrioid cysts: ultrasoundguided aspiration, excision, and coagulation [195].

Ultrasound (US)-guided aspiration may be the treatment of choice in the case of ovarian endometriomas, but high recurrence rates have been reported (60-90\%) [196]. Some authors have proposed sclerotherapy to reduce the recurrence rate, but the possibility of spillage of the endometriotic fluid may lead to adhesion development [197]. Since the endometriotic fluid consists mainly of clotted blood, US-guided aspiration may increase the risk of bacterial infection and ovarian abscess formation with further oophorectomy. US-guided aspiration and sclerotherapy should be performed in patients without indications for surgery, patients with increased anesthetic risk, or women with severe adhesions [195].

Laparoscopic drainage and coagulation may be another surgical technique but there is an increased recurrence rate of endometrioma and problems of future conceiving in comparison with excision [198]. Laparoscopic cystectomy remains the optimal therapy for ovarian endometriomas. Most of the complications related to ovarian reserve occur during the cystectomy techniques, so the question is in whom and when cystectomy should be performed [195].
Medical treatment can include gonadotropin-releasing hormone $(\mathrm{GnRH})$ agonists in severe cases. Other potential non-surgical treatments incorporate hormone receptor (estrogen or progesterone) modulators, immune modulators, aromatase inhibitors, and anti-angiogenic drugs [199-201].

Guidelines from the American Society for Reproductive Medicine [193, 194] and the European Society of Human Reproduction and Embryology are focused on pain and infertility treatment, as these are possible complications of endometriosis. The treatment options in cases of pelvic pain include a trial of nonsteroidal anti-inflammatory drugs and hormonal therapy (combined oral contraceptives). All hormonal medicines, which encompass combined oral contraceptives, progestins, and GnRH agonists, possess similar effectiveness, but their side effects and costs are different. Estrogen-progestin add-back therapy is recommended in the case of GnRH agonist prescription. GnRH agonists are not recommended for adolescents as a result of their effects on bone. The levonorgestrel intrauterine system is effective in some patients. Superovulation with intrauterine insemination show reliable results in the case of infertility. Ovarian suppression is not effective in promoting spontaneous pregnancy. The use of a GnRH agonist for 3-6 months is recommended before in vitro fertilization and surgical ablation of endometriosis in stage I or II disease.

There is a novel treatment option with GnRH antagonists in the case of severe pain associated with endometriosis. The mechanism of action competitively inhibits GnRH receptors in the pituitary gland and leads to a reduction in circulating gonadotropins and estradiol. This mechanism is different from that of GnRH agonists which desensitize GnRH receptors in the pituitary gland and cause depletion of pituitary gonadotropins that leads to complete suppression of estradiol to levels that are equivalent to bilateral oophorectomy conditions [202].

There are some prospective treatment methods based on signaling molecules and pathways of endometriosis [13]. JAK/STAT (Janus kinases (JAKs), signal transducer and 
activator of transcription proteins (STAT)) signaling pathway plays an important role in endometriosis. STAT activation provides effects of PDGF, FGF, IL-6, hepatocyte growth factor (HGF), and VEGF. The JAK/STAT pathway is a target for novel therapeutics because it is relatively simple mechanistically, providing a direct translation of extracellular signals into a transcriptional response. Among the small molecule inhibitors of this pathway are leflunomide (a JAK inhibitor) and atiprimod (a STAT3 inhibitor) [13]. In the TGF $\beta / S M A D$ signaling pathway, the SMAD proteins are the only family of transcription factors known to propagate TGF $\beta$ signals. Lerdelimumab (a recombinant human IgG4 targeting TGF $\beta 2$ ) and metelimumab (a human monoclonal IgG4 against TGF $\beta 1$ ) can inhibit TGF $\beta$ signaling [13]. The effects of EGF and TNF $\alpha$ are mediated via the MEK (mitogenactivated protein kinase kinase) pathway. Selumetinib and other MEK/ERK inhibitors are being primarily developed and studied for cancer treatment. However, the role of the MEK/ ERK pathway in endometriosis suggests that these therapeutic strategies may lend themselves equally well to this disease [13].

To date, none of the offered strategies for the treatment of endometriosis leads to complete treatment and avoidance of disease recurrence. Traditional surgical treatment does not always promote complete recovery of ovarian functions and does not exclude endometriosis recurrence. Besides, there is a risk of transformation of endometrioid heterotopic foci into an atypical form with associated development of endometriosis-associated tumors. At the same time, the molecular mechanisms of such transformation remain unclear, complicating prevention and early diagnosis. The application of molecular science with rapidly advancing knowledge of neoplasms and modern technologies creates an opportunity to identify the origin of endometriosis, especially among patients who are at risk of developing cancer. To separate patients at risk of endometriosis-associated cancer from those with benign disease, the application of highly sensitive and specific novel molecular biomarkers should be explored. A combination of epidemiological, pathological, and molecular risk stratification will be required [203].

\section{CONCLUSIONS}

Endometriosis is a complex disease, and its origin remains unclear. It creates certain health and social problems that warrant intensive scientific research to manage this disorder. At present, endometriosis is considered likely a precancerous lesion, having much in common in genetic abnormalities. In addition, its behavior and association with certain ovarian cancers are categorized as endometriosis-associated ovarian cancers. Many reports clearly reveal that not all types and not all cases of endometriosis transform to malignancy. Nevertheless, there is still a risk that reasonably cannot be ignored. This perspective demands another clinical approach to endometriosis management.

Patients suffering from endometriosis may be divided into several groups according to malignancy risk. There are schemes and principles to establish categories (i.e., ROMA (risk of ovarian malignancy algorithm), RMI (risk of malignancy index), IOTA (International Ovarian Tumor Analysis) simple rules) that are based on serum biomarkers, body mass index (BMI), ultrasound findings etc. A great effort is being made to find a non-invasive test to properly and comprehensively diagnose endometriosis. Many biomarkers have been investigated that are based on molecular pathways from cell surface and nuclear macromolecules. However, results are contradictory in that some serum biomarkers are elevated in the case of endometriosis while subsequent histological examination shows benign-looking endometriotic glands and stroma. It is justifiable to conjecture that there is a developmental time lag between cell atypia and tissue atypical changes. Additional reports have documented subtle histological changes in endometriosis epithelial cells that precede atypical transformation but without any correlation between atypical changes and biomarker investigations. Moreover, the question regarding the malignant transformation in endometriomas compared to 
other types of endometriosis remains unanswered. In conclusion, it should be noted that the pathogenesis of endometriosis, its origin, and malignant transformation are not a separate monolithic disease process, but rather a group of converging processes that make it even more challenging for future investigation.

\section{ACKNOWLEDGEMENTS}

Funding. The work was financially supported by the RFBR under scientific project No. 18-33-20209 and completed as part of the state task 0090_2019_0006. The study partially also supported by the Russian Academic Excellence project "5-100" for the Sechenov University, Moscow, Russia. No Rapid Service and Open Access Fees were received by the journal for the publication of this article.

Authorship. All named authors meet the International Committee of Medical Journal Editors (ICMJE) criteria for authorship for this article, take responsibility for the integrity of the work as a whole, and have given their approval for this version to be published.

Disclosures. Liudmila M. Mikhaleva, Aleksandr I. Davydov, Olga I. Patsap, Elizaveta V. Mikhaylenko, Vladimir N. Nikolenko, Margarita E. Neganova, Sergey G. Klochkov, Siva G. Somasundaram, Cecil E. Kirkland and Gjumrakch Aliev have nothing to disclose.

Compliance with Ethics Guidelines. This article is based on previously conducted studies and does not contain any studies with human participants or animals performed by any of the authors.

Data Availability. All data generated or analyzed during this study are included in this published article/as supplementary information files.

Open Access. This article is licensed under a Creative Commons Attribution-NonCommercial 4.0 International License, which permits any non-commercial use, sharing, adaptation, distribution and reproduction in any medium or format, as long as you give appropriate credit to the original author(s) and the source, provide a link to the Creative Commons licence, and indicate if changes were made. The images or other third party material in this article are included in the article's Creative Commons licence, unless indicated otherwise in a credit line to the material. If material is not included in the article's Creative Commons licence and your intended use is not permitted by statutory regulation or exceeds the permitted use, you will need to obtain permission directly from the copyright holder. To view a copy of this licence, visit http://creativecommons.org/licenses/by$\mathrm{nc} / 4.0 /$.

\section{REFERENCES}

1. Adamyan L, Andreeva E, Apolikhina I, et al. Endometrioz: diagnostika, lechenie i reabilitatsiya: federal'nye klinicheskie rekomendatsii po vedeniyu bol'nykh. Izd-vo Nauchnogo tsentra akusherstva, ginekologii i perinatologii im. V.I.Kulakova, Moscow 2013.

2. Zařratiants OV, Adamian LV, Andreeva EN, et al. Molecular biological features of ectopic and eutopic endometrium in genital endometriosis. Arkh Patol. 2010;72:6-12.

3. Gajbhiye R, Bendigeri T, Ghuge A, et al. Panel of autoimmune markers for noninvasive diagnosis of minimal-mild endometriosis. Reprod Sci. 2017;24: 413-20.

4. Socolov R, Socolov D, Sindilar A, Pavaleanu I. An update on the biological markers of endometriosis. Minerva Ginecol. 2017;69:462-7.

5. Pearce CL, Stram DO, Ness RB, et al. Population distribution of lifetime risk of ovarian cancer in the United States. Cancer Epidemiol Biomark Prev. 2015;24:671-6.

6. Niguez Sevilla I, Machado Linde F, Marín Sánchez MDP, et al. Prognostic importance of atypical endometriosis with architectural hyperplasia versus cytologic atypia in endometriosis-associated ovarian cancer. J Gynecol Oncol. 2019;30:e63.

7. Munksgaard PS, Blaakaer J. The association between endometriosis and ovarian cancer: a review of 
histological, genetic and molecular alterations. Gynecol Oncol. 2012;124:164-9.

8. Vinatier D, Cosson M, Dufour P. Is endometriosis an endometrial disease? Eur J Obstet Gynecol Reprod Biol. 2000;91:113-25.

9. Vinatier D, Dufour P, Leroy JL. The mechanisms of endometriosis. Rev Prat. 1999;49:254-7.

10. Larosa M, Facchini F, Pozzoli G, Leone M, Grande M, Monica B. Endometriosis: aetiopathogenetic basis. Urologia. 2010;77(Suppl 17):1-11.

11. Drosdzol A, Skrzypulec V. Endometriosis in pediatric and adolescent gynecology. Ginekol Pol. 2008;79:133-6.

12. Sasson IE, Taylor HS. Stem cells and the pathogenesis of endometriosis. Ann N Y Acad Sci. 2008;1127: 106-15.

13. Aznaurova YB, Zhumataev MB, Roberts TK, Aliper AM, Zhavoronkov AA. Molecular aspects of development and regulation of endometriosis. Reprod Biol Endocrinol. 2014;12:50.

14. Macer ML, Taylor HS. Endometriosis and infertility: a review of the pathogenesis and treatment of endometriosis-associated infertility. Obstet Gynecol Clin North Am. 2012;39:535-49.

15. Adachi M, Nasu K, Tsuno A, Yuge A, Kawano Y, Narahara H. Attachment to extracellular matrices is enhanced in human endometriotic stromal cells: a possible mechanism underlying the pathogenesis of endometriosis. Eur J Obstet Gynecol Reprod Biol. 2011;155:85-8.

16. Laganà AS, Vitale SG, Salmeri FM, et al. Unus pro omnibus, omnes pro uno: a novel, evidence-based, unifying theory for the pathogenesis of endometriosis. Med Hypotheses. 2017;103:10-20.

17. Lin Q, Ding SJ, Zhu TH, Li TT, Huang XF, Zhang $\mathrm{XM}$. Role and clinical significance of coagulation and inflammatory factors in moderate and severe ovarian endometriosis. Zhonghua Fu Chan Ke Za Zhi. 2018;53:167-71.

18. Lushnikova A. Clinico-morphological analysis and immunohistochemical characteristics of inner end external genital endometriosis. Ph.D. dissertation, Institute of Regional Pathology and Pathomorphology 2012.

19. Vitale SG, Capriglione S, Peterlunger I, et al. The role of oxidative stress and membrane transport systems during endometriosis: a fresh look at a busy corner. Oxid Med Cell Longev. 2018;2018:7924021.
20. Jiang Q-Y, Wu R-J. Growth mechanisms of endometriotic cells in implanted places: a review. Gynecol Endocrinol. 2012;28:562-7.

21. Lin Y-J, Lai M-D, Lei H-Y, Wing L-YC. Neutrophils and macrophages promote angiogenesis in the early stage of endometriosis in a mouse model. Endocrinology. 2006;147:1278-86.

22. Bergqvist A, Bruse C, Carlberg M, Carlström K. Interleukin 1beta, interleukin-6, and tumor necrosis factor-alpha in endometriotic tissue and in endometrium. Fertil Steril. 2001;75:489-95.

23. Sacco K, Portelli M, Pollacco J, Schembri-Wismayer $\mathrm{P}$, Calleja-Agius J. The role of prostaglandin E2 in endometriosis. Gynecol. 2012;28:134-8.

24. Pedraza C, Geberhiwot T, Ingerpuu S, et al. Monocytic cells synthesize, adhere to, and migrate on laminin-8 (alpha 4 beta 1 gamma 1). J Immunol Baltim. 2000;165:5831-8.

25. Lessey BA, Castelbaum AJ, Sawin SW, et al. Aberrant integrin expression in the endometrium of women with endometriosis. J Clin Endocrinol Metab. 1994;79:643-9.

26. Hinck L, Näthke IS, Papkoff J, Nelson WJ. Dynamics of cadherin/catenin complex formation: novel protein interactions and pathways of complex assembly. J Cell Biol. 1994;125:1327-40.

27. Shaco-Levy R, Sharabi S, Benharroch D, Piura B, Sion-Vardy N. Matrix metalloproteinases 2 and 9, E-cadherin, and beta-catenin expression in endometriosis, low-grade endometrial carcinoma and non-neoplastic eutopic endometrium. Eur J Obstet Gynecol Reprod Biol. 2008;139:226-32.

28. Ris HW. The integration of a comprehensive medical program in a juvenile correctional institution. J Am Med Womens Assoc (1972). 1975;30:367-78.

29. Matsuzaki S, Darcha C. Involvement of the Wnt/ $\beta$ catenin signaling pathway in the cellular and molecular mechanisms of fibrosis in endometriosis. PLoS One. 2013;8:e76808.

30. Ueda M, Yamashita Y, Takehara M, et al. Gene expression of adhesion molecules and matrix metalloproteinases in endometriosis. Gynecol Endocrinol. 2002;16:391-402.

31. Clevers $H$, Nusse $R$. Wnt/ $\beta$-catenin signaling and disease. Cell. 2012;149:1192-205.

32. Béliard A, Donnez J, Nisolle M, Foidart JM. Localization of laminin, fibronectin, E-cadherin, and integrins in endometrium and endometriosis. Fertil Steril. 1997;67:266-72. 
33. Poncelet C, Leblanc M, Walker-Combrouze F, et al. Expression of cadherins and CD44 isoforms in human endometrium and peritoneal endometriosis. Acta Obstet Gynecol Scand. 2002;81:195-203.

34. Fujimoto J, Ichigo S, Hori M, Tamaya T. Alteration of E-cadherin, alpha- and beta-catenin mRNA expression in human uterine endometrium during the menstrual cycle. Gynecol Endocrinol. 1996;10: 187-91.

35. Bartel DP. MicroRNAs: genomics, biogenesis, mechanism, and function. Cell. 2004;116:281-97.

36. Teague EMCO, Print CG, Hull ML. The role of microRNAs in endometriosis and associated reproductive conditions. Hum Reprod Update. 2010;16: 142-65.

37. Hawkins SM, Creighton CJ, Han DY, et al. Functional microRNA involved in endometriosis. Mol Endocrinol. 2011;25:821-32.

38. Nothnick WB, Swan K, Flyckt R, Falcone T, Graham A. Human endometriotic lesion expression of the miR-144-3p/miR-451a cluster, its correlation with markers of cell survival and origin of lesion content. Sci Rep. 2019;9:8823.

39. Kennedy S, Mardon H, Barlow D. Familial endometriosis. J Assist Reprod Genet. 1995;12:32-4.

40. Hadfield RM, Mardon HJ, Barlow DH, Kennedy SH. Endometriosis in monozygotic twins. Fertil Steril. 1997;68:941-2.

41. Stefansson H, Geirsson RT, Steinthorsdottir V, et al. Genetic factors contribute to the risk of developing endometriosis. Hum Reprod. 2002;17:555-9.

42. Vanhie A, Peterse D, Beckers A, et al. Plasma miRNAs as biomarkers for endometriosis. Hum Reprod. 2019;34:1650-60.

43. Chang CY-Y, Chen Y, Lai M-T, et al. BMPR1B upregulation via a miRNA binding site variation defines endometriosis susceptibility and CA125 levels. PLoS One. 2013;8:e80630.

44. Gupta D, Hull ML, Fraser I, et al. Endometrial biomarkers for the non-invasive diagnosis of endometriosis. Cochrane Database Syst Rev. 2016;4: CD012165.

45. Nisenblat V, Prentice L, Bossuyt PMM, Farquhar C, Hull ML, Johnson N. Combination of the non-invasive tests for the diagnosis of endometriosis. Cochrane Database Syst Rev. 2016;7:CD012281.

46. Fiala L, Bob P, Raboch J. Oncological markers CA125, CA 19-9 and endometriosis. Medicine (Baltimore). 2018;97:e13759.
47. Giudice LC, Kao LC. Endometriosis. Lancet. 2004;364:1789-99.

48. Fassbender A, Vodolazkaia A, Saunders P, et al. Biomarkers of endometriosis. Fertil Steril. 2013;99: 1135-45.

49. Fassbender A, Dorien O, De Moor B, et al. Biomarkers of endometriosis. In: Harada T, editor. Endometriosis: pathogenesis and treatment. Tokyo: Springer Japan; 2014. p. 321-339.

50. D'Hooghe TM, Mihalyi AM, Simsa P, et al. Why we need a noninvasive diagnostic test for minimal to mild endometriosis with a high sensitivity. Gynecol Obstet Invest. 2006;62:136-8.

51. May KE, Conduit-Hulbert SA, Villar J, Kirtley S, Kennedy SH, Becker CM. Peripheral biomarkers of endometriosis: a systematic review. Hum Reprod Update. 2010;16:651-74.

52. Fassbender A, Burney RO, D'Hooghe T, Giudice L. Update on biomarkers for the detection of endometriosis. BioMed Res Int. 2015;2015:130854.

53. Rogers PAW, D'Hooghe TM, Fazleabas A, et al. Defining future directions for endometriosis research: workshop report from the 2011 World Congress of Endometriosis in Montpellier, France. Reprod Sci. 2013;20:483-99.

54. Rogers PAW, D'Hooghe TM, Fazleabas A, et al. Priorities for endometriosis research: recommendations from an international consensus workshop. Reprod Sci. 2009;16:335-46.

55. D’Hooghe T, Vodolazkaia A, Kyama C, Mwenda J, Simoens S. Health economics of endometriosis. In: Rombauts L, Tsaltas J, Maher P, Healy D, editors. Endometriosis. Malden: Blackwell; 2008. p. 1-16.

56. Zetterberg H. Blood-based biomarkers for Alzheimer's disease-an update. J Neurosci Methods. 2019;319:2-6.

57. Surinova S, Schiess R, Hüttenhain R, Cerciello F, Wollscheid B, Aebersold R. On the development of plasma protein biomarkers. J Proteome Res. 2011;10:5-16.

58. Othman EE-DR, Hornung D, Al-Hendy A. Biomarkers of endometriosis. Expert Opin Med Diagn. 2008;2:741-52.

59. Silsirivanit A. Glycosylation markers in cancer. Adv Clin Chem. 2019;89:189-21313.

60. Hoskins W, Perez C, Young R, Barakat R, Markman M, Randall M, editors. Principles and practice of gynecologic oncology. 4th ed. Philadelphia: LWW; 2004. 
61. Ünsal M, Kimyon Comert G, Karalok A, et al. The preoperative serum CA125 can predict the lymph node metastasis in endometrioid-type endometrial cancer. Ginekol Pol. 2018;89:599-606.

62. Crosby DA, Glover LE, Martyn F, Wingfield M. CA125 measured during menstruation can be misleading. Ir Med J. 2018;111:738.

63. Akinwunmi BO, Babic A, Vitonis AF, et al. Chronic medical conditions and CA125 levels among women without ovarian cancer. Cancer Epidemiol Biomark Prev. 2018;27:1483-90.

64. Hirsch M, Duffy J, Davis CJ, Nieves Plana M, Khan KS, International Collaboration to Harmonise Outcomes, and Measures for Endometriosis. Diagnostic accuracy of cancer antigen 125 for endometriosis: a systematic review and meta-analysis. BJOG. 2016;123:1761-8.

65. Hirsch M, Duffy JMN, Deguara CS, Davis CJ, Khan KS. Diagnostic accuracy of cancer antigen 125 (CA125) for endometriosis in symptomatic women: a multi-center study. Eur J Obstet Gynecol Reprod Biol. 2017;210:102-7.

66. Karimi-Zarchi M, Dehshiri-Zadeh N, Sekhavat L, Nosouhi F. Correlation of CA-125 serum level and clinico-pathological characteristic of patients with endometriosis. Int J Reprod Biomed. 2016;14:713-8.

67. Tuten A, Kucur M, Imamoglu M, et al. Copeptin is associated with the severity of endometriosis. Arch Gynecol Obstet. 2014;290:75-82.

68. Hsu CC, Yang BC, Wu MH, Huang KE. Enhanced interleukin-4 expression in patients with endometriosis. Fertil Steril. 1997;67:1059-64.

69. Hirata T, Osuga Y, Hamasaki K, et al. Interleukin (IL)-17A stimulates IL-8 secretion, cyclooxygensase2 expression, and cell proliferation of endometriotic stromal cells. Endocrinology. 2008;149:1260-7.

70. Zhang L, Khayat A, Cheng H, Graves DT. The pattern of monocyte recruitment in tumors is modulated by MCP-1 expression and influences the rate of tumor growth. Lab Investig. 1997;76:579-90.

71. Kelly RW, Carr GG, Riley SC. The inhibition of synthesis of a beta-chemokine, monocyte chemotactic protein-1 (MCP-1) by progesterone. Biochem Biophys Res Commun. 1997;239:557-61.

72. Rockfield S, Raffel J, Mehta R, Rehman N, Nanjundan M. Iron overload and altered iron metabolism in ovarian cancer. Biol Chem. 2017;398:995-1007.

73. Andrews NC. Disorders of iron metabolism. N Engl J Med. 1999;341:1986-95.
74. Mancias JD, Wang X, Gygi SP, Harper JW, Kimmelman AC. Quantitative proteomics identifies NCOA4 as the cargo receptor mediating ferritinophagy. Nature. 2014;509:105-9.

75. Wang J, Pantopoulos K. Regulation of cellular iron metabolism. Biochem J. 2011;434:365-81.

76. Defrère S, Van Langendonckt A, Vaesen S, et al. Iron overload enhances epithelial cell proliferation in endometriotic lesions induced in a murine model. Hum Reprod. 2006;21:2810-6.

77. Van Langendonckt A, Casanas-Roux F, Donnez J. Iron overload in the peritoneal cavity of women with pelvic endometriosis. Fertil Steril. 2002;78: 712-8.

78. Yamaguchi K, Mandai M, Toyokuni S, et al. Contents of endometriotic cysts, especially the high concentration of free iron, are a possible cause of carcinogenesis in the cysts through the iron-induced persistent oxidative stress. Clin Cancer Res. 2008;14:32-40.

79. Seidman JD. The presence of mucosal iron in the fallopian tube supports the "incessant menstruation hypothesis" for ovarian carcinoma. Int J Gynecol Pathol. 2013;32:454-8.

80. Emori MM, Drapkin R. The hormonal composition of follicular fluid and its implications for ovarian cancer pathogenesis. Reprod Biol Endocrinol. 2014;12:60.

81. Shigeta S, Toyoshima M, Kitatani K, Ishibashi M, Usui T, Yaegashi N. Transferrin facilitates the formation of DNA double-strand breaks via transferrin receptor 1: the possible involvement of transferrin in carcinogenesis of high-grade serous ovarian cancer. Oncogene. 2016;35:3577-86.

82. Singh AK, Chattopadhyay R, Chakravarty B, Chaudhury K. Markers of oxidative stress in follicular fluid of women with endometriosis and tubal infertility undergoing IVF. Reprod Toxicol. 2013;42: 116-24.

83. Da Broi MG, de Albuquerque FO, de Andrade AZ, Cardoso RL, Jordão Junior AA, Navarro PA. Increased concentration of 8-hydroxy-2'-deoxyguanosine in follicular fluid of infertile women with endometriosis. Cell Tissue Res. 2016;366: 231-42.

84. Sanchez AM, Papaleo E, Corti L, et al. Iron availability is increased in individual human ovarian follicles in close proximity to an endometrioma compared with distal ones. Hum Reprod. 2014;29: 577-83. 
85. Benaglia L, Paffoni A, Mangiarini A, et al. Intrafollicular iron and ferritin in women with ovarian endometriomas. Acta Obstet Gynecol Scand. 2015;94:646-53.

86. Bahar-Shany K, Brand H, Sapoznik S, et al. Exposure of fallopian tube epithelium to follicular fluid mimics carcinogenic changes in precursor lesions of serous papillary carcinoma. Gynecol Oncol. 2014;132:322-7.

87. Huang H-S, Chu S-C, Hsu C-F, et al. Mutagenic, surviving and tumorigenic effects of follicular fluid in the context of p53 loss: initiation of fimbria carcinogenesis. Carcinogenesis. 2015;36:1419-28.

88. Lattuada D, Uberti F, Colciaghi B, et al. Fimbrial cells exposure to catalytic iron mimics carcinogenic changes. Int J Gynecol Cancer. 2015;25:389-98.

89. Uberti F, Morsanuto V, Lattuada D, et al. Protective effects of vitamin D3 on fimbrial cells exposed to catalytic iron damage. J Ovarian Res. 2016;9:34.

90. Yamaguchi K, Mandai M, Oura T, et al. Identification of an ovarian clear cell carcinoma gene signature that reflects inherent disease biology and the carcinogenic processes. Oncogene. 2010;29: 1741-52.

91. Joseph S, Mahale SD. Endometriosis Knowledgebase: a gene-based resource on endometriosis. Database (Oxford). 2019;2019:baz062.

92. Ponomarenko I, Polonikov A, Verzilina I, Churnosov M. Molecular-genetic determinants of the development of endometriosis. Probl Gynecol Obstet Perinatol. 2019;18:82-6.

93. Anglesio MS, Papadopoulos N, Ayhan A, et al. Cancer-associated mutations in endometriosis without cancer. N Engl J Med. 2017;376:1835-48.

94. Vestergaard AL, Thorup K, Knudsen UB, et al. Oncogenic events associated with endometrial and ovarian cancers are rare in endometriosis. Mol Hum Reprod. 2011;17:758-61.

95. Bischoff FZ, Heard M, Simpson JL. Somatic DNA alterations in endometriosis: high frequency of chromosome 17 and p53 loss in late-stage endometriosis. J Reprod Immunol. 2002;55:49-644.

96. Sáinz de la Cuesta R, Izquierdo M, Cañamero M, Granizo JJ, Manzarbeitia F. Increased prevalence of p53 overexpression from typical endometriosis to atypical endometriosis and ovarian cancer associated with endometriosis. Eur J Obstet Gynecol Reprod Biol. 2004;113:87-93.

97. Laudanski P, Szamatowicz J, Kowalczuk O, Kuźmicki M, Grabowicz M, Chyczewski L. Expression of selected tumor suppressor and oncogenes in endometrium of women with endometriosis. Hum Reprod. 2009;24:1880-90.

98. Yamamoto S, Tsuda H, Takano M, Iwaya K, Tamai S, Matsubara O. PIK3CA mutation is an early event in the development of endometriosis-associated ovarian clear cell adenocarcinoma. J Pathol. 2011;225: 189-94.

99. Sato N, Tsunoda $H$, Nishida $M$, et al. Loss of heterozygosity on 10q23.3 and mutation of the tumor suppressor gene PTEN in benign endometrial cyst of the ovary: possible sequence progression from benign endometrial cyst to endometrioid carcinoma and clear cell carcinoma of the ovary. Cancer Res. 2000;60:7052-6.

100. Anglesio MS, Bashashati A, Wang YK, et al. Multifocal endometriotic lesions associated with cancer are clonal and carry a high mutation burden. J Pathol. 2015;236:201-9.

101. Wiegand KC, Shah SP, Al-Agha OM, et al. ARID1A mutations in endometriosis-associated ovarian carcinomas. N Engl J Med. 2010;363:1532-43.

102. Fuseya C, Horiuchi A, Hayashi A, et al. Involvement of pelvic inflammation-related mismatch repair abnormalities and microsatellite instability in the malignant transformation of ovarian endometriosis. Hum Pathol. 2012;43:1964-72.

103. Grassi T, Calcagno A, Marzinotto S, et al. Mismatch repair system in endometriotic tissue and eutopic endometrium of unaffected women. Int J Clin Exp Pathol. 2015;8:1867-77.

104. Yang W, Zhang Y, Fu F, Li R. High-resolution arraycomparative genomic hybridization profiling reveals 20q13.33 alterations associated with ovarian endometriosis. Gynecol Endocrinol. 2013;29:603-7.

105. Mafra F, Mazzotti D, Pellegrino R, et al. Copy number variation analysis reveals additional variants contributing to endometriosis development. J Assist Reprod Genet. 2017;34:117-24.

106. Worley MJ, Liu S, Hua Y, et al. Molecular changes in endometriosis-associated ovarian clear cell carcinoma. Eur J Cancer. 2015;51:1831-42.

107. Guo S-W. Cancer driver mutations in endometriosis: variations on the major theme of fibrogenesis. Reprod Med Biol. 2018;17:369-97.

108. Stamp JP, Gilks CB, Wesseling M, et al. BAF250a expression in atypical endometriosis and endometriosis-associated ovarian cancer. Int $\mathrm{J}$ Gynecol Cancer. 2016;26:825-32. 
109. Chene G, Ouellet V, Rahimi K, Barres V, Provencher D, Mes-Masson AM. The ARID1A pathway in ovarian clear cell and endometrioid carcinoma, contiguous endometriosis, and benign endometriosis. Int J Gynaecol Obstet. 2015;130:27-30.

110. Martínez-Salgado C, Rodríguez-Peña AB, LópezNovoa JM. Involvement of small Ras GTPases and their effectors in chronic renal disease. Cell Mol Life Sci. 2008;65:477-92.

111. Rojas JM, Santos E. Ras genes and human cancer: different implications and different roles. Curr Genom. 2002;3:295-311.

112. Takai Y, Sasaki T, Matozaki T. Small GTP-binding proteins. Physiol Rev. 2001;81:153-208.

113. Baselga J. The EGFR as a target for anticancer therapy-focus on cetuximab. Eur $J$ Cancer. 2001;37(Suppl 4):S16-22.

114. Stephen AG, Esposito D, Bagni RK, McCormick F. Dragging ras back in the ring. Cancer Cell. 2014;25: 272-81.

115. Cox AD, Fesik SW, Kimmelman AC, Luo J, Der CJ. Drugging the undruggable RAS: mission possible? Nat Rev Drug Discov. 2014;13:828-51.

116. Karapetis CS, Khambata-Ford S, Jonker DJ, et al. K-ras mutations and benefit from cetuximab in advanced colorectal cancer. $\mathrm{N}$ Engl J Med. 2008;359:1757-65.

117. Guo DF, Sun YL, Hamet P, Inagami T. The angiotensin II type 1 receptor and receptor-associated proteins. Cell Res. 2001;11:165-80.

118. Wang L, Proud CG. Regulation of the phosphorylation of elongation factor 2 by MEK-dependent signalling in adult rat cardiomyocytes. FEBS Lett. 2002;531:285-9.

119. Santibáñez JF, Guerrero J, Quintanilla M, Fabra A, Martínez J. Transforming growth factor-beta1 modulates matrix metalloproteinase-9 production through the Ras/MAPK signaling pathway in transformed keratinocytes. Biochem Biophys Res Commun. 2002;296:267-73.

120. Che W, Abe J, Yoshizumi M, et al. p160 Bcr mediates platelet-derived growth factor activation of extracellular signal-regulated kinase in vascular smooth muscle cells. Circulation. 2001;104: 1399-406.

121. Robin P, Boulven I, Bôle-Feysot C, Tanfin Z, Leiber D. Contribution of PKC-dependent and -independent processes in temporal ERK regulation by ET-1, PDGF, and EGF in rat myometrial cells. Am J Physiol Cell Physiol. 2004;286:C798-806.
122. Lin C-C, Shyr M-H, Chien C-S, et al. Thrombinstimulated cell proliferation mediated through activation of Ras/Raf/MEK/MAPK pathway in canine cultured tracheal smooth muscle cells. Cell Signal. 2002;14:265-75.

123. Rakhila H, Al-Akoum M, Bergeron M-E, et al. Promotion of angiogenesis and proliferation cytokines patterns in peritoneal fluid from women with endometriosis. J Reprod Immunol. 2016;116:1-6.

124. Zhang Q, Duan J, Liu X, Guo S-W. Platelets drive smooth muscle metaplasia and fibrogenesis in endometriosis through epithelial-mesenchymal transition and fibroblast-to-myofibroblast transdifferentiation. Mol Cell Endocrinol. 2016;428:1-16.

125. Loverro G, Maiorano E, Napoli A, Selvaggi L, Marra E, Perlino E. Transforming growth factor-beta 1 and insulin-like growth factor-1 expression in ovarian endometriotic cysts: a preliminary study. Int J Mol Med. 2001;7:423-9.

126. Guo S-W, Du Y, Liu X. Endometriosis-derived stromal cells secrete thrombin and thromboxane A2, inducing platelet activation. Reprod Sci. 2016;23: 1044-52.

127. Nakao T, Chishima F, Sugitani M, Tsujimura R, Hayashi C, Yamamoto T. Expression of angiotensin II types 1 and 2 receptors in endometriotic lesions. Gynecol Obstet Invest. 2017;82:294-302.

128. Dinulescu DM, Ince TA, Quade BJ, Shafer SA, Crowley D, Jacks T. Role of K-ras and Pten in the development of mouse models of endometriosis and endometrioid ovarian cancer. Nat Med. 2005;11:63-70.

129. Shahrabi-Farahani M, Shahbazi S, Mahdian R, Amini-Moghaddam S. K-Ras 4A transcript variant is up-regulated in eutopic endometrium of endometriosis patients during proliferative phase of menstrual cycle. Arch Gynecol Obstet. 2015;292: 225-9.

130. Farahani MS, Shahbazi S, Moghaddam SA, Mahdian R. Evaluation of KRAS gene expression and LCS6 variant in genomic and cell-free DNA of Iranian women with endometriosis. Reprod Sci. 2015;22: 679-84.

131. Yotova IY, Quan P, Leditznig N, Beer U, Wenzl R, Tschugguel W. Abnormal activation of Ras/Raf/ MAPK and RhoA/ROCKII signalling pathways in eutopic endometrial stromal cells of patients with endometriosis. Hum Reprod. 2011;26:885-97.

132. Cheng C, Licence D, Cook E, et al. Activation of mutated K-ras in donor endometrial epithelium and stroma promotes lesion growth in an intact 
immunocompetent murine model of endometriosis. J Pathol. 2011;224:261-9.

133. Stewart CJR, Leung Y, Walsh MD, Walters RJ, Young JP, Buchanan DD. KRAS mutations in ovarian lowgrade endometrioid adenocarcinoma: association with concurrent endometriosis. Hum Pathol. 2012;43:1177-83.

134. Ueda M, Yamashita Y, Takehara M, et al. Survivin gene expression in endometriosis. J Clin Endocrinol Metab. 2002;87:3452-9.

135. Laudanski P, Szamatowicz J, Ramel P. Matrix metalloproteinase-13 and membrane type-1 matrix metalloproteinase in peritoneal fluid of women with endometriosis. Gynecol Endocrinol. 2005;21: 106-10.

136. Chung HW, Lee JY, Moon H-S, et al. Matrix metalloproteinase-2, membranous type 1 matrix metalloproteinase, and tissue inhibitor of metalloproteinase- 2 expression in ectopic and eutopic endometrium. Fertil Steril. 2002;78:787-95.

137. Levakov S, Gromova T, Kedrova A, Sheshukova N. Endometriosis-associated ovarian cancer. Women Reprod Syst Tumors. 2016;12:47-51.

138. Yamamoto S, Tsuda H, Takano M, Tamai S, Matsubara O. Loss of ARID1A protein expression occurs as an early event in ovarian clear-cell carcinoma development and frequently coexists with PIK3CA mutations. Mod Pathol. 2012;25:615-24.

139. Wu R-C, Wang T-L, Shih I-M. The emerging roles of ARID1A in tumor suppression. Cancer Biol Ther. 2014;15:655-64.

140. Nishikimi K, Kiyokawa T, Tate S, Iwamoto M, Shozu M. ARID1A expression in ovarian clear cell carcinoma with an adenofibromatous component. Histopathology. 2015;67:866-71.

141. Guan B, Rahmanto YS, Wu R-C, et al. Roles of deletion of Arid1a, a tumor suppressor, in mouse ovarian tumorigenesis. J Natl Cancer Inst. 2014;106: dju146.

142. Tomasetti C, Vogelstein B. Cancer etiology. Variation in cancer risk among tissues can be explained by the number of stem cell divisions. Science. 2015;347:78-81.

143. Minlikeeva AN, Freudenheim JL, Eng KH, et al. History of comorbidities and survival of ovarian cancer patients, results from the Ovarian Cancer Association Consortium. Cancer Epidemiol Biomark Prev. 2017;26:1470-3.

144. Zou Y, Zhou J-Y, Guo J-B, et al. The presence of KRAS, PPP2R1A and ARID1A mutations in 101
Chinese samples with ovarian endometriosis. Mutat Res. 2018;809:1-5.

145. Yamamoto S, Tsuda H, Takano M, Tamai S, Matsubara O. PIK3CA mutations and loss of ARID1A protein expression are early events in the development of cystic ovarian clear cell adenocarcinoma. Virchows Arch Int J Pathol. 2012;460:77-87.

146. Yin Y, Shen WH. PTEN: a new guardian of the genome. Oncogene. 2008;27:5443-53.

147. Puc J, Keniry M, Li HS, et al. Lack of PTEN sequesters CHK1 and initiates genetic instability. Cancer Cell. 2005;7:193-204.

148. de Abreu JP, Rebelatto CLK, Savari CA, et al. The effect of mesenchymal stem cells on fertility in experimental retrocervical endometriosis. Rev Bras Ginecol Obstet. 2017;39:217-23.

149. Puc J, Parsons R. PTEN loss inhibits CHK1 to cause double stranded-DNA breaks in cells. Cell Cycle Georget Tex. 2005;4:927-9.

150. Obata K, Hoshiai H. Common genetic changes between endometriosis and ovarian cancer. Gynecol Obstet Invest. 2000;50(Suppl 1):39-433.

151. Obata K, Morland SJ, Watson RH, et al. Frequent PTEN/MMAC mutations in endometrioid but not serous or mucinous epithelial ovarian tumors. Cancer Res. 1998;58:2095-7.

152. Xu B, Hamada S, Kusuki I, Itoh R, Kitawaki J. Possible involvement of loss of heterozygosity in malignant transformation of ovarian endometriosis. Gynecol Oncol. 2011;120:239-46.

153. Zhang H, Zhao X, Liu S, Li J, Wen Z, Li M. 17betaE2 promotes cell proliferation in endometriosis by decreasing PTEN via NFkappaB-dependent pathway. Mol Cell Endocrinol. 2010;317:31-433.

154. Martini M, Ciccarone M, Garganese G, et al. Possible involvement of hMLH1, p16(INK4a) and PTEN in the malignant transformation of endometriosis. Int J Cancer. 2002;102:398-406.

155. Rai P, Shivaji S. The role of DJ-1 in the pathogenesis of endometriosis. PLoS One. 2011;6:e18074.

156. Li M-Q, Luo X-Z, Meng Y-H, et al. CXCL8 enhances proliferation and growth and reduces apoptosis in endometrial stromal cells in an autocrine manner via a CXCR1-triggered PTEN/AKT signal pathway. Hum Reprod. 2012;27:2107-16.

157. Kim TH, Yu Y, Luo L, et al. Activated AKT pathway promotes establishment of endometriosis. Endocrinology. 2014;155:1921-30. 
158. Lv J, Zhu Q, Jia X, Yu N, Li Q. In vitro and in vivo effects of tumor suppressor gene PTEN on endometriosis: an experimental study. Med Sci Monit. 2016;22:3727-36.

159. Ferretti E, Schulz H, Talarico D, Blasi F, Berthelsen J. The PBX-regulating protein PREP1 is present in different PBX-complexed forms in mouse. Mech Dev. 1999;83:53-64.

160. Selleri L, Depew MJ, Jacobs Y, et al. Requirement for Pbx1 in skeletal patterning and programming chondrocyte proliferation and differentiation. Development. 2001;128:3543-57.

161. Marshall H, Nonchev S, Sham MH, Muchamore I, Lumsden A, Krumlauf R. Retinoic acid alters hindbrain Hox code and induces transformation of rhombomeres $2 / 3$ into a $4 / 5$ identity. Nature. 1992;360:737-41.

162. Dubrulle J, McGrew MJ, Pourquié O. FGF signaling controls somite boundary position and regulates segmentation clock control of spatiotemporal Hox gene activation. Cell. 2001;106:219-32.

163. Miller C, Pavlova A, Sassoon DA. Differential expression patterns of Wnt genes in the murine female reproductive tract during development and the estrous cycle. Mech Dev. 1998;76:91-9.

164. Cunha GR. Stromal induction and specification of morphogenesis and cytodifferentiation of the epithelia of the Mullerian ducts and urogenital sinus during development of the uterus and vagina in mice. J Exp Zool. 1976;196:361-70.

165. Branford WW, Benson GV, Ma L, Maas RL, Potter SS. Characterization of Hoxa-10/Hoxa-11 transheterozygotes reveals functional redundancy and regulatory interactions. Dev Biol. 2000;224:373-87.

166. Vainio S, Heikkilä M, Kispert A, Chin N, McMahon AP. Female development in mammals is regulated by Wnt-4 signalling. Nature. 1999;397:405-9.

167. Mericskay M, Kitajewski J, Sassoon D. Wnt5a is required for proper epithelial-mesenchymal interactions in the uterus. Development. 2004;131:2061-72.

168. Hayashi K, Yoshioka S, Reardon SN, et al. WNTs in the neonatal mouse uterus: potential regulation of endometrial gland development. Biol Reprod. 2011;84:308-19.

169. Kühl M, Sheldahl LC, Park M, Miller JR, Moon RT. The Wnt/Ca2+ pathway: a new vertebrate Wnt signaling pathway takes shape. Trends Genet TIG. 2000;16:279-83.

170. Reya T, Clevers H. Wnt signalling in stem cells and cancer. Nature. 2005;434:843-50.
171. Valkenburg KC, Graveel CR, Zylstra-Diegel CR, Zhong Z, Williams BO. Wnt/ $\beta$-catenin signaling in normal and cancer stem cells. Cancers. 2011;3: 2050-79.

172. Kuo H-H, Huang C-Y, Ueng S-H, Huang K-G, Lee C-L, Yen C-F. Unexpected epithelial ovarian cancers arising from presumed endometrioma: a 10-year retrospective analysis. Taiwan J Obstet Gynecol. 2017;56:55-61.

173. Gadducci A, Lanfredini N, Tana R. Novel insights on the malignant transformation of endometriosis into ovarian carcinoma. Gynecol Endocrinol. 2014;30: $612-7$.

174. Kurman RJ, International Agency for Research on Cancer, World Health Organization. WHO classification of tumours of female reproductive organs, vol. 4. Lyon: International Agency for Research on Cancer; 2014.

175. Kaku T, Ogawa S, Kawano Y, et al. Histological classification of ovarian cancer. Med Electron Microsc. 2003;36:9-17.

176. Anglesio MS, Yong PJ. Endometriosis-associated ovarian cancers. Clin Obstet Gynecol. 2017;60: 711-27.

177. Xiao W, Awadallah A, Xin W. Loss of ARID1A/ BAF250a expression in ovarian endometriosis and clear cell carcinoma. Int J Clin Exp Pathol. 2012;5: 642-50.

178. Coatham M, Li X, Karnezis AN, et al. Concurrent ARID1A and ARID1B inactivation in endometrial and ovarian dedifferentiated carcinomas. Mod Pathol. 2016;29:1586-93.

179. Wendel JRH, Wang $X$, Hawkins SM. The endometriotic tumor microenvironment in ovarian cancer. Cancers. 2018;10:261.

180. Ciriello G, Miller ML, Aksoy BA, Senbabaoglu Y, Schultz N, Sander C. Emerging landscape of oncogenic signatures across human cancers. Nat Genet. 2013;45:1127-33.

181. Sapalidis K, Machairiotis N, Zarogoulidis $\mathrm{P}$, et al. Genes' interactions: a major contributor to the malignant transformation of endometriosis. Int J Mol Sci. 2019;20:1842.

182. Berker B, Seval M. Problems with the diagnosis of endometriosis. Womens Health. 2015;11:597-601.

183. Moss EL, Hollingworth J, Reynolds TM. The role of CA125 in clinical practice. J Clin Pathol. 2005;58: 308-12. 
184. Huhtinen K, Suvitie P, Hiissa J, et al. Serum HE4 concentration differentiates malignant ovarian tumours from ovarian endometriotic cysts. $\mathrm{Br} \mathrm{J}$ Cancer. 2009;100:1315-9.

185. Leyland N, Casper R, Laberge P, Singh SS, SOGC. Endometriosis: diagnosis and management. J Obstet Gynaecol Can. 2010;32:S1-32.

186. Wykes CB, Clark TJ, Khan KS. Accuracy of laparoscopy in the diagnosis of endometriosis: a systematic quantitative review. BJOG. 2004;111:1204-12.

187. Hori Y, SAGES Guidelines Committee. Diagnostic laparoscopy guidelines: This guideline was prepared by the SAGES Guidelines Committee and reviewed and approved by the Board of Governors of the Society of American Gastrointestinal and Endoscopic Surgeons (SAGES), November 2007. Surg Endosc. 2008;22:1353-83.

188. Burney RO, Giudice LC. Pathogenesis and pathophysiology of endometriosis. Fertil Steril. 2012;98: 511-9.

189. Eskenazi B, Warner ML. Epidemiology of endometriosis. Obstet Gynecol Clin North Am. 1997;24:235-58.

190. Burghaus S, Häberle L, Schrauder MG, et al. Endometriosis as a risk factor for ovarian or endometrial cancer-results of a hospital-based case-control study. BMC Cancer. 2015;15:751.

191. Wykes CB, Clark TJ, Chakravati S, Mann CH, Gupta JK. Efficacy of laparoscopic excision of visually diagnosed peritoneal endometriosis in the treatment of chronic pelvic pain. Eur J Obstet Gynecol Reprod Biol. 2006;125:129-33.

192. Moon H-S, Shim JE, Lee SR, Jeong K. The comparison of robotic single-site surgery to single-port laparoendoscopic surgery for the treatment of advanced-stage endometriosis. J Laparoendosc Adv Surg Tech A. 2018;28:1483-8.

193. Practice Committee of the American Society for Reproductive Medicine. Endometriosis and infertility. Fertil Steril. 2006;86:S156-160.
194. Practice Committee of the American Society for Reproductive Medicine. Treatment of pelvic pain associated with endometriosis: a committee opinion. Fertil Steril. 2014;101:927-35.

195. Karaman Y, Uslu H. Complications and their management in endometriosis surgery. Womens Health. 2015; 11:685-92.

196. Chan LY, So WW, Lao TT. Rapid recurrence of endometrioma after transvaginal ultrasound-guided aspiration. Eur J Obstet Gynecol Reprod Biol. 2003;109:196-8.

197. Okagaki R, Osuga Y, Momoeda M, Tsutsumi O, Taketani Y. Laparoscopic findings after ultrasoundguided transvaginal ethanol sclerotherapy for ovarian endometrial cyst. Hum Reprod. 1999;14: 270.

198. Vercellini P, Somigliana E, Viganò P, Abbiati A, Barbara G, Crosignani PG. Surgery for endometriosis-associated infertility: a pragmatic approach. Hum Reprod. 2009;24:254-69.

199. Bedaiwy MA, Alfaraj S, Yong P, Casper R. New developments in the medical treatment of endometriosis. Fertil Steril. 2017;107:555-65.

200. Streuli I, de Ziegler D, Borghese B, Santulli P, Batteux F, Chapron C. New treatment strategies and emerging drugs in endometriosis. Expert Opin Emerg Drugs. 2012;17:83-104.

201. Streuli I, de Ziegler D, Santulli P, et al. An update on the pharmacological management of endometriosis. Expert Opin Pharmacother. 2013;14:291-305.

202. Taylor HS, Giudice LC, Lessey BA, et al. Treatment of endometriosis-associated pain with elagolix, an oral GnRH antagonist. N Engl J Med. 2017;377: 28-40.

203. Dawson A, Fernandez ML, Anglesio M, Yong PJ, Carey MS. Endometriosis and endometriosis-associated cancers: new insights into the molecular mechanisms of ovarian cancer development. Ecancermedicalscience. 2018;12:803. 